\title{
Inter-comparison of MAX-DOAS measurements of tropospheric HONO slant column densities and vertical profiles during the CINDI-2 campaign
}

Yang Wang ${ }^{1}$, Arnoud Apituley ${ }^{2}$, Alkiviadis Bais ${ }^{3}$, Steffen Beirle ${ }^{1}$, Nuria Benavent ${ }^{4}$, Alexander Borovski ${ }^{5}$, Ilya Bruchkouski ${ }^{6}$, Ka Lok Chan ${ }^{7,8}$, Sebastian Donner ${ }^{1}$, Theano Drosoglou ${ }^{3}$, Henning Finkenzeller ${ }^{9,10}$, Martina M. Friedrich ${ }^{11}$, Udo Frieß ${ }^{12}$, David Garcia-Nieto ${ }^{4}$, Laura Gómez-Martín ${ }^{13}$, François Hendrick ${ }^{11}$, Andreas Hilboll ${ }^{14}$, Junli Jin ${ }^{15}$, Paul Johnston ${ }^{16}$, Theodore K. Koenig ${ }^{9,10}$, Karin Kreher ${ }^{17}$, Vinod Kumar ${ }^{1}$, Aleksandra Kyuberis ${ }^{18}$, Johannes Lampel ${ }^{12,19}$, Cheng Liu ${ }^{20}$, Haoran Liu ${ }^{20}$, Jianzhong Ma ${ }^{21}$, Oleg L. Polyansky ${ }^{18,22}$, Oleg Postylyakov ${ }^{5}$, Richard Querel ${ }^{16}$, Alfonso Saiz-Lopez ${ }^{4}$, Stefan Schmitt ${ }^{12}$, Xin Tian ${ }^{23,24}$, Jan-Lukas Tirpitz ${ }^{12}$, Michel Van Roozendael ${ }^{11}$, Rainer Volkamer ${ }^{9,10}$, Zhuoru Wang ${ }^{8}$, Pinhua Xie ${ }^{24}$, Chengzhi Xing ${ }^{25}$, Jin Xu${ }^{24}$, Margarita Yela ${ }^{13}$, Chengxin Zhang ${ }^{25}$, and Thomas Wagner ${ }^{1}$

${ }^{1}$ Max Planck Institute for Chemistry, Mainz, Germany

${ }^{2}$ Royal Netherlands Meteorological Institute (KNMI), De Bilt, the Netherlands

${ }^{3}$ Laboratory of Atmospheric Physics, Aristotle University of Thessaloniki, Thessaloniki, Greece

${ }^{4}$ Department of Atmospheric Chemistry and Climate, Institute of Physical Chemistry Rocasolano (CSIC), Madrid, Spain

${ }^{5}$ A. M. Obukhov Institute of Atmospheric Physics, Russian Academy of Sciences, Moscow, Russia

${ }^{6}$ National Ozone Monitoring Research and Education Center BSU (NOMREC BSU),

Belarusian State University, Minsk, Belarus

${ }^{7}$ Meteorologisches Institut, Ludwig-Maximilians-Universität München, Munich, Germany

${ }^{8}$ Remote Sensing Technology Institute, German Aerospace Center (DLR), Oberpfaffenhofen, Germany

${ }^{9}$ Department of Chemistry, University of Colorado Boulder, Boulder, CO, USA

${ }^{10}$ Cooperative Institute for Research in Environmental Sciences, Boulder, CO, USA

${ }^{11}$ Royal Belgian Institute for Space Aeronomy, Brussels, Belgium

${ }^{12}$ Institute of Environmental Physics, University of Heidelberg, Heidelberg, Germany

${ }^{13}$ National Institute of Aerospatial Technology, Madrid, Spain

${ }^{14}$ Institute of Environmental Physics, University of Bremen, Bremen, Germany

${ }^{15}$ Meteorological Observation Center, China Meteorological Administration, Beijing, China

${ }^{16}$ National Institute of Water \& Atmospheric Research (NIWA), Lauder, New Zealand

${ }^{17}$ BK Scientific, Mainz, Germany

${ }^{18}$ Institute of Applied Physics, Russian Academy of Sciences, Nizhny Novgorod, Russia

${ }^{19}$ Airyx GmbH, Justus-von-Liebig-Str. 14, 69214 Eppelheim, Germany

${ }^{20}$ Department of Precision Machinery and Precision Instrumentation, University of Science and Technology of China, Hefei, Anhui, China

${ }^{21}$ Chinese Academy of Meteorology Science, China Meteorological Administration, Beijing, China

${ }^{22}$ Department of Physics and Astronomy, University College London, Gower St, London, WC1E 6BT, UK

${ }^{23}$ Institutes of Physical Science and Information Technology, Anhui University, Hefei, 230601, China

${ }^{24}$ Anhui Institute of Optics and Fine Mechanics, Chinese Academy of Sciences, Hefei, China

${ }^{25}$ School of Earth and Space Sciences, University of Science and Technology of China, Hefei, Anhui, China

Correspondence: Yang Wang (y.wang@mpic.de)

Received: 29 November 2019 - Discussion started: 4 February 2020

Revised: 28 May 2020 - Accepted: 8 July 2020 - Published: 29 September 2020

Published by Copernicus Publications on behalf of the European Geosciences Union. 
Abstract. We present the inter-comparison of delta slant column densities (SCDs) and vertical profiles of nitrous acid (HONO) derived from measurements of different multiaxis differential optical absorption spectroscopy (MAXDOAS) instruments and using different inversion algorithms during the Second Cabauw Inter-comparison campaign for Nitrogen Dioxide measuring Instruments (CINDI2) in September 2016 at Cabauw, the Netherlands (51.97 $\mathrm{N}$, $\left.4.93^{\circ} \mathrm{E}\right)$. The HONO vertical profiles, vertical column densities (VCDs), and near-surface volume mixing ratios are compared between different MAX-DOAS instruments and profile inversion algorithms for the first time. Systematic and random discrepancies of the HONO results are derived from the comparisons of all data sets against their median values. Systematic discrepancies of HONO delta SCDs are observed in the range of $\pm 0.3 \times 10^{15}$ molec. $\mathrm{cm}^{-2}$, which is half of the typical random discrepancy of $0.6 \times$ $10^{15}$ molec. $\mathrm{cm}^{-2}$. For a typical high HONO delta SCD of $2 \times 10^{15}$ molec. $\mathrm{cm}^{-2}$, the relative systematic and random discrepancies are about $15 \%$ and $30 \%$, respectively. The inter-comparison of HONO profiles shows that both systematic and random discrepancies of HONO VCDs and nearsurface volume mixing ratios (VMRs) are mostly in the range of $\sim \pm 0.5 \times 10^{14}$ molec. $\mathrm{cm}^{-2}$ and $\sim \pm 0.1 \mathrm{ppb}$ (typically $\sim 20 \%$ ). Further we find that the discrepancies of the retrieved HONO profiles are dominated by discrepancies of the HONO delta SCDs. The profile retrievals only contribute to the discrepancies of the HONO profiles by $\sim 5 \%$. However, some data sets with substantially larger discrepancies than the typical values indicate that inappropriate implementations of profile inversion algorithms and configurations of radiative transfer models in the profile retrievals can also be an important uncertainty source. In addition, estimations of measurement uncertainties of HONO dSCDs, which can significantly impact profile retrievals using the optimal estimation method, need to consider not only DOAS fit errors, but also atmospheric variability, especially for an instrument with a DOAS fit error lower than $\sim 3 \times 10^{14}$ molec. $\mathrm{cm}^{-2}$. The MAX-DOAS results during the CINDI- 2 campaign indicate that the peak HONO levels (e.g. near-surface VMRs of $\sim 0.4 \mathrm{ppb}$ ) often appeared in the early morning and below $0.2 \mathrm{~km}$. The near-surface VMRs retrieved from the MAXDOAS observations are compared with those measured using a co-located long-path DOAS instrument. The systematic differences are smaller than 0.15 and $0.07 \mathrm{ppb}$ during early morning and around noon, respectively. Since true HONO values at high altitudes are not known in the absence of real measurements, in order to evaluate the abilities of profile inversion algorithms to respond to different HONO profile shapes, we performed sensitivity studies using synthetic HONO delta SCDs simulated by a radiative transfer model with assumed HONO profiles. The tests indicate that the profile inversion algorithms based on the optimal estimation method with proper configurations can reproduce the different HONO profile shapes well. Therefore we conclude that the features of HONO accumulated near the surface derived from MAX-DOAS measurements are expected to represent the ambient HONO profiles well.

\section{Introduction}

Multi-axis differential optical absorption spectroscopy (MAX-DOAS) is widely used as a ground-based remote sensing technique for retrieving lower tropospheric vertical profiles of trace gases (e.g. $\mathrm{NO}_{2}, \mathrm{SO}_{2}, \mathrm{HCHO}$ ) and aerosols from sequential measurements of ultraviolet and visible spectra of scattered sunlight recorded at multiple elevation angles (Hönninger and Platt, 2002; Bobrowski et al., 2003; Van Roozendael et al., 2003; Hönninger et al., 2004; Wagner et al., 2004; Wittrock et al., 2004). MAX-DOAS instruments have been developed with different optical and mechanical systems by different research groups and companies in order to meet the requirements of high accuracy and automatic operation. MAX-DOAS measurements have been widely used, especially for the validation of satellite products (e.g. Ma et al., 2013; Kanaya et al., 2014; Jin et al., 2016a; Wang et al., 2017a; Liu et al., 2019). Inversion procedures of MAX-DOAS measurements normally contain two steps: (1) spectral analysis to derive tropospheric differential slant column densities (delta SCDs) of trace gases; (2) retrieval of vertical profiles from the dependencies of the delta SCDs on elevation angle. Note that the definitions of SCD, dSCD, and delta SCD are given in Sect. 2.2.1. Different programs, e.g. QDOAS (Danckaert et al., 2017), WINDOAS (Fayt and van Roozendael, 2009) and DOASIS (Kraus et al., 2006), have been developed for the spectral analysis based on the DOAS technique (Platt and Stutz, 2008, and references therein). The spectral analysis can strongly depend on the configuration of fit parameters, e.g. wavelength ranges, cross sections, polynomials, and intensity offset corrections. Inversion algorithms of vertical profiles of trace gases and aerosols have been developed in previous studies based on the optimal estimation (OE) method (Rodgers, 2000; Frieß et al., 2006, 2011; Wittrock, 2006; Irie et al., 2008, 2011; Clémer et al., 2010; Yilmaz, 2012; Hartl and Wenig, 2013; Y. Wang et al., 2013a, b, 2017b; Chan et al., 2018; Bösch et al., 2018) and parameterized approaches (Li et al., 2010, 2013; Vlemmix et al., 2010, 2011, 2015; Wagner et al., 2011; Beirle et al., 2018), respectively. Both types of retrievals require radiative transfer model (RTM) simulations to calculate air mass factors (AMFs). These algorithms utilize different iterative approaches, different software implementations, and different RTMs. For inversion algorithms based on the $\mathrm{OE}$ method, retrieval results can be significantly affected by the choices of the a priori constraints, e.g. a priori profiles, co- 
variance of uncertainties, and aerosol optical properties. For parameterized approaches, only the profile scenarios which are considered for building the look-up table can be retrieved from real measurements. Like for the profiles retrieved by $\mathrm{OE}$, the retrieved profiles can be considerably impacted by the assumed profile parameters, aerosol optical properties, or fit and profile selection approaches. In order to generate harmonized data sets from worldwide MAX-DOAS observations, it is necessary to evaluate the consistency of MAXDOAS results derived from measurements of different MAXDOAS instruments and using different programs for spectral analysis and profile inversion. For this purpose, a series of campaigns, including the Cabauw Inter-comparison campaign of Nitrogen Dioxide measuring Instruments (CINDI) in the Netherlands in June-July 2009 (http://projects.knmi. nl/cindi/, last access: 20 September 2020, Piters et al., 2012), the Multi Axis DOAS - Comparison campaign for Aerosols and Trace gases (MAD-CAT) in Germany in June and July 2013 (http://joseba.mpch-mainz.mpg.de/mad_cat.htm, last access: 20 September 2020), and the CINDI-2 campaign in the Netherlands in September 2016 (http://www. tropomi.eu/data-products/cindi-2, last access: 20 September 2020, Apituley et al., 2019), were organized. Thirty-six MAX-DOAS instruments designed and operated by 24 different institutes across the world participated in the CINDI-2 campaign. In previous studies, $\mathrm{SCDs}$ of $\mathrm{NO}_{2}, \mathrm{HCHO}, \mathrm{O}_{3}$, and $\mathrm{O}_{4}$ retrieved from different instruments have been intercompared (e.g. Roscoe et al., 2010; Pinardi et al., 2013; Zieger et al., 2011; Irie et al., 2011; Friess et al., 2016; Wang et al., 2017c; Peters et al., 2017). Wang et al. (2017c) present inter-comparisons of SCDs of nitrous acid (HONO), which has $\sim 10$ times lower absorption signals than $\mathrm{NO}_{2}$, during the MAD-CAT campaign. Further studies compared profile results of aerosol extinction and $\mathrm{NO}_{2}$ and $\mathrm{HCHO}$ concentrations retrieved from different instruments and by different inversion algorithms (Frieß et al., 2016, 2019; Tirpitz et al., 2020). In this study we focus on the inter-comparison of HONO results (dSCDs and profiles) derived from MAXDOAS measurements during the recent CINDI-2 campaign.

In the past decade, several studies have been performed investigating the daytime sources of HONO to unravel their potential contributions to the $\mathrm{OH}$ radical concentration and the tropospheric oxidation capacity (Alicke et al., 2003; K1effmann et al., 2005; Acker et al., 2006; Monks et al., 2009; Elshorbany et al., 2010). The gas-phase reaction of NO with the OH radical (Stuhl and Niki, 1972, and Pagsberg et al., 1997) mostly determines the daytime HONO concentration. However, field measurements (Neftel et al., 1996; Kleffmann et al., 2005; Sörgel et al., 2011; Li et al., 2012, 2014; Wong et al., 2012) and laboratory studies (Akimoto et al., 1987; Rohrer et al., 2005) reported that the well-known gasphase reactions can often not explain the observed high daytime concentrations of HONO. To explain this discrepancy, several suggestions were made: heterogeneous reactions on various surfaces such as the ground, forests, buildings, and aerosols (e.g. Su et al., 2008, 2011; Li et al., 2014, and references therein), emissions from soil (e.g. Su et al., 2011, and references therein), and a potential gas-phase reaction between $\mathrm{HO}_{x}$ and $\mathrm{NO}_{x}$ ( $\mathrm{Li}$ et al., 2014). Since vertical profiles of HONO can indicate the height of the dominant HONO sources, MAX-DOAS measurements of HONO have drawn major attention in recent years. However, HONO retrievals from MAX-DOAS measurements are still challenging due to typically low HONO volume mixing ratios (VMRs) of $<$ $1 \mathrm{ppb}$ (corresponding to a typical optical depth of $<0.005$ ), even in polluted regions. Although several studies have reported HONO profile retrievals using MAX-DOAS measurements at different locations (e.g. Hendrick et al., 2014; Ryan et al., 2018; Wang et al., 2018a), so far few efforts have been made to study the consistency of HONO results, especially the vertical profiles, retrieved from different MAXDOAS instruments and using different inversion algorithms. In our previous study (Wang et al., 2017c) based on measurements made during the MAD-CAT campaign, we evaluated discrepancies of HONO SCDs between seven MAX-DOAS instruments, quantified error sources of the DOAS fits, and concluded on recommended DOAS fit parameters based on sensitivity studies. In this study, we extend the HONO intercomparison activity to more MAX-DOAS instruments and include also the comparison of the HONO vertical profiles retrieved during the CINDI-2 campaign. Furthermore, we evaluate the dependence of the retrieved HONO profiles on different shapes and discuss the optimal a priori settings based on synthetic studies using RTM simulations. The effects of varying vertical grid intervals on the profile retrievals are also discussed based on sensitivity tests.

This paper is structured as follows. Section 2 provides an overview of the CINDI-2 campaign, comparison schemes of HONO delta SCD and profile results, the RTM simulations for the analysis of synthetic spectra, and cloud classifications introduced for the inter-comparisons. Sections 3 and 4 present inter-comparison results of HONO delta SCDs and profiles, respectively, derived from real measurements by the participating instruments. The sensitivity studies of HONO profile inversions based on synthetic analysis are given in Sect. 5. The conclusions are presented in Sect. 6.

\section{CINDI-2 inter-comparison campaign}

\subsection{CINDI-2 campaign and HONO inter-comparison activities}

The CINDI-2 campaign was held in the period from 12 to 28 September 2016 at the remote-sensing site of the CESAR station $\left(51.971^{\circ} \mathrm{N}, 4.927^{\circ} \mathrm{E}\right)$ (http://www.cesar-observatory. nl/, last access: 20 September 2020) in a rural area in Cabauw, the Netherlands. The measurement site is surrounded by pasture and farmland and is located $\sim 20 \mathrm{~km}$ southwest of the city of Utrecht and $\sim 30 \mathrm{~km}$ east of the 
city of Rotterdam. Thirty-six MAX-DOAS instruments participated in the campaign and were operated by different research groups. Different optical, electrical, and mechanical systems with different spectrometers were used in the different MAX-DOAS instruments. In order to optimize the synchronization of the measurements for the inter-comparisons, all MAX-DOAS instruments were installed close to each other and measured following a consistent protocol (see http: //www.tropomi.eu/data-products/planning-information, last access: 20 September 2020). Some instruments measure also at different azimuth angles and are categorized in the following as $2 \mathrm{D}$ systems, whereas others can only measure at one fixed azimuth angle and are categorized as 1D systems. Because of these differences, 2D systems and 1D systems followed different measurement protocols. One-dimensional systems continuously measured at the fixed azimuth direction of $287^{\circ}$ with four elevation sequences in each hour. Twodimensional systems routinely measured at seven different azimuth angles in each hour and in the time slot of $15 \mathrm{~min}$ at the beginning of each hour at the same azimuth angle $\left(287^{\circ}\right)$ as the 1D systems. Therefore in the first $15 \mathrm{~min}$ of each hour, all instruments measure at the same azimuth angle of $287^{\circ}$ and used the same elevation sequence of $1,2,3,4,5,6,8$, 15,30 , and $90^{\circ}$. The same integration time of $1 \mathrm{~min}$ for individual measurements was applied by all the instruments.

Further information about the campaign and the participating instruments can be found in Apituley et al. (2019) and Kreher et al. (2019). So far CINDI-2 data have been used in Donner et al. (2019) for the study on the accuracy of different elevation calibration methods, in Kreher et al. (2019) for carrying out a semi-blind inter-comparison of $\mathrm{NO}_{2}, \mathrm{O}_{4}, \mathrm{O}_{3}$ and HCHO slant column densities, and in Frieß et al. (2019) and Tirpitz et al. (2020) for the study of the consistency of profile retrievals of aerosols, $\mathrm{NO}_{2}$, and $\mathrm{HCHO}$ derived from different inversion programs and instruments based on synthetic and measured spectra. Additionally, the CINDI-2 data were used by Wang et al. (2018b) to develop new retrieval algorithms for tropospheric ozone profiles and by Beirle et al. (2019) to demonstrate the performance of the MAPA profile inversion algorithm.

Thirteen MAX-DOAS instruments operated by different researchers joined this study on the retrievals of tropospheric HONO. An overview of the participants and their instruments and analysis tools is provided in Table 1. The comparison activities were performed in two steps. First, the consistency of the HONO delta SCDs was evaluated, and then an inter-comparison of the derived vertical profiles was performed. The details of the retrieval settings, comparison schemes, and participating instruments and algorithms are given in Sect. 2.2 and 2.3, respectively.

\subsection{Inter-comparison of tropospheric HONO slant column densities}

\subsubsection{Baseline retrieval settings and comparison schemes}

Baseline DOAS retrieval settings were selected based on the recommended settings from a previous study during the MAD-CAT campaign (Wang et al., 2017c). The parameters of the baseline settings are given in Table 2. Different participants applied the baseline settings using different DOAS fit programs independent of each other. Absorption cross sections of $\mathrm{HONO}, \mathrm{NO}_{2}, \mathrm{O}_{3}, \mathrm{BrO}, \mathrm{O}_{4}, \mathrm{HCHO}$, and $\mathrm{H}_{2} \mathrm{O}$ were convolved with the slit function of the individual instruments before being included in DOAS fits. The slant column density (SCD) represents the trace gas concentration integrated along the light path. Differential SCDs (dSCDs) are the direct output from a DOAS fit of a measured spectrum and represent the difference of the SCDs in a measured spectrum and a Fraunhofer reference spectrum. The Fraunhofer reference spectrum is usually measured at the elevation angle of $90^{\circ}$ in order to acquire the shortest light path in the troposphere. If both the measured off-zenith spectrum and the Fraunhofer reference spectrum in a DOAS fit are recorded at approximately the same solar zenith angle (SZA), the retrieved dSCD only contains the absorptions along the light path in the troposphere, since both measurements have almost the same stratospheric light path. Therefore, in such cases, the retrieved dSCD directly represents the tropospheric SCD. In the pioneering study of Hönninger et al. (2004), it is referred to as delta SCD. Since delta SCDs are normally used in the retrievals of tropospheric vertical profiles, we first intercompare the HONO delta SCDs between the different instruments. There are two procedures to retrieve delta SCDs from off-zenith MAX-DOAS measurements, which use two different Fraunhofer reference spectra (FRS), namely the socalled "sequential FRS" and "daily noon FRS". The "sequential FRS" is derived from interpolation of two spectra measured in zenith view before and after an elevation sequence to match the time of the off-zenith measurements. The "daily noon FRS" is obtained from the mean of all zenith-sky spectra acquired between 11:30:00 and 11:41:00 UTC on individual days. The differential SCDs retrieved using the "sequential FRS" can directly be regarded as the delta SCDs. In contrast, a post-processing is needed to convert the differential SCDs (dSCDs) retrieved using the "daily noon FRS" into delta SCDs. For individual HONO dSCDs retrieved from off-zenith measurements, a reference $\mathrm{dSCD}$ can be derived by a time interpolation of the HONO dSCDs retrieved from zenith measurements before and after the off-zenith measurement. The HONO delta SCDs is then derived by subtracting this reference dSCD from the corresponding off-zenith dSCDs. The mathematical derivation of delta dSCDs with the two procedures has been discussed in Sect. 3.1 of Wang et al. (2017c). Although the "sequential" FRS can compen- 


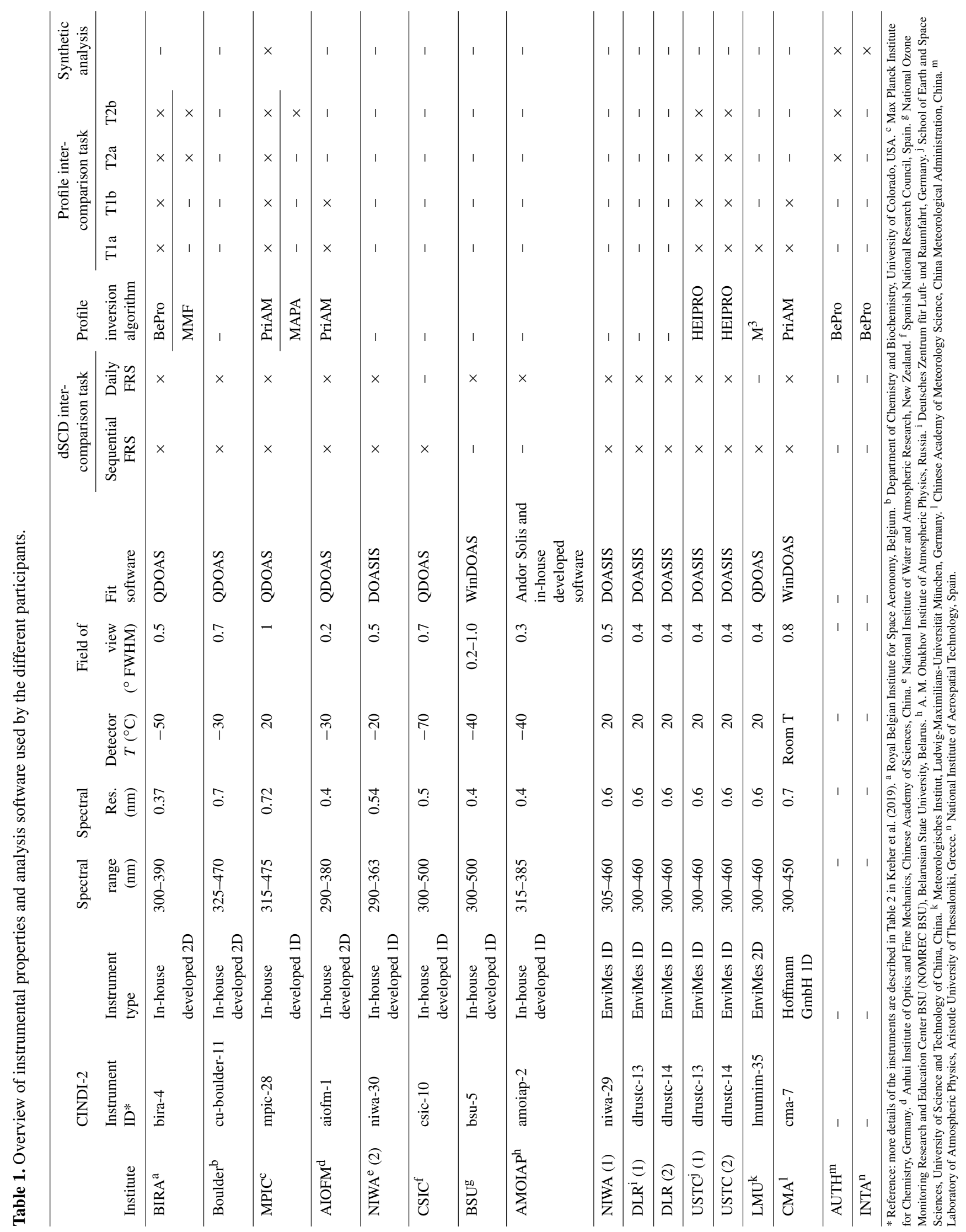


sate for the effects of instability of instrumental properties on DOAS retrievals, the "daily noon FRS" is easier to implement in typical DOAS programs than the "sequential FRS". Therefore the "daily noon FRS" was often used in previous studies. In this study, comparison activities of HONO delta SCDs are separated into two parts: for retrievals using either the "sequential FRS" or the "daily noon FRS", the results of the different instruments are compared. Additionally, for individual instruments, the HONO delta SCDs retrieved using the two different FRS are also compared in order to quantify the potential bias of the HONO retrievals due to the different FRS procedures.

\subsubsection{Participating instruments}

The institutes and instruments participating in the SCD intercomparison activities are listed in Table 1. It should be noted that "USTC (1)" and "USTC (2)" represent two data sets derived from two MAX-DOAS instruments operated by the "USTC" researchers. Additionally, the spectra recorded by the two "USTC" instruments are independently analysed by the "DLR" researchers, which are marked as "DLR (1)" and "DLR (2)". Considering the different measurement protocols followed by the 2D system and 1D system instruments, only coincident measurements in the first $15 \mathrm{~min}$ of each hour are included in the inter-comparison activities. The participating instruments are separated into three groups, consisting of in-house developed instruments by individual groups, EnviMes instruments developed at the University of Heidelberg (Lampel et al., 2015) and recently commercialized (http://www.airyx.de, last access: 20 September 2020), and Mini-DOAS instruments produced in Germany by Hoffmann GmbH (http://www.hmm.de/, last access: 20 September 2020).

\subsection{Inter-comparisons of tropospheric HONO profiles}

\subsubsection{Baseline retrieval settings and inversion algorithms}

HONO profiles are retrieved from the elevation angle dependency of the HONO delta SCDs using inversion algorithms. Five inversion algorithms based on the optimal estimation (OE) method are used in this study: PriAM (Y. Wang et al., 2013a, b, 2017b), BePro (Clémer et al., 2010), MMF (Friedrich et al., 2019), HEIPRO (Frieß et al., 2006, 2011), and $\mathrm{M}^{3}$ (Chan et al., 2018). Different from the other algorithms, MAPA (Beirle et al., 2019) implemented by the "MPIC" participants is based on a profile parameterization. The corresponding algorithms implemented by individual participants are listed in Table 1. Note that PriAM, BePro, and HEIPRO are independently implemented by several participants. Some parameters are harmonized between the different inversion algorithms. Information on these parameters and on the atmospheric properties used in the RTM is sum- marized in Table 3. Note that no assumptions about the measurement uncertainty covariance, a priori profiles, and a priori covariance matrices are made in MAPA. The wavelength of the RTM simulations of the HONO AMFs for the profile retrievals is $355 \mathrm{~nm}$, representing the effective wavelength of the HONO absorption in the spectral range of DOAS fits of HONO delta SCDs. The effective wavelength is calculated by weighting the wavelengths by the HONO cross-section values in the spectral range of $335-373 \mathrm{~nm}$ of the HONO DOAS fits. The atmospheric properties and aerosol properties are set based on typical conditions near the measurement site during the CINDI-2 campaign period. Profiles are retrieved in the altitude range of 0 to $4 \mathrm{~km}$ with a grid of $200 \mathrm{~m}$. Vertical profiles of aerosol extinction are required as an input for the HONO profile retrievals and were retrieved around $360 \mathrm{~nm}$ from $\mathrm{O}_{4}$ delta $\mathrm{SCDs}$, which are retrieved from the MAX-DOAS measurements in the spectral range of 338-370 nm. The details of the aerosol retrievals can be found in Tirpitz et al. (2020). Following previous studies (e.g. Hendrick et al., 2014; Wang et al., 2018), the covariance of the measurement uncertainties is set to a square of $100 \%$ of the DOAS fit error of the HONO dSCDs for the diagonal elements and zero for the extra-diagonal elements. The a priori profile is arbitrarily set as an exponentially decreasing profile with a vertical column density (VCD) of $3 \times 10^{14}$ molec. $\mathrm{cm}^{-2}$ and a scaling height (SH) of $0.1 \mathrm{~km}$. The selection of the a priori profile shape is based on the fact that HONO is typically accumulated at altitudes close to the surface (Hendrick et al., 2014; Wang et al., 2018). Similar to measurement uncertainties, and following the previous studies (e.g. Hendrick et al., 2014; Wang et al., 2018), the covariance of the a priori profile $\left(S_{\mathrm{a}}\right)$ is set to a square of $100 \%$ of a priori values for the diagonal elements. The extra-diagonal elements are calculated using a Gaussian function based on the neighbouring diagonal elements with a correlation length of $200 \mathrm{~m}$.

For the algorithms based on the optimal estimation method, each of them used different RTMs as the forward model and applied different iterative procedures. PriAM and HEIPRO use the RTM SCIATRAN, version 2 (Rozanov et al., 2005). BePro, MMF, and $\mathrm{M}^{3}$ use the RTMs LIDORT (Spurr et al., 2008), VLIDORT (Spurr et al., 2013), and LibRadTran (Mayer and Kylling, 2005; Emde et al., 2016), respectively. Another important difference is that in order to avoid negative concentrations of the retrieved results (which are not possible in the real atmosphere), the retrievals are done in logarithmic space (see details in Yilmaz, 2012) by PriAM, HEIPRO, and MMF. Since distribution probabilities of retrieved profiles around a priori profiles become asymmetric due to the inversion in the logarithm space, the sensitivity of the inversion to large values is larger than that in the linear space. A non-linear iterative procedure is applied for the inversion of both aerosol and trace gas profiles in PriAM, HEIPRO, and MMF, whereas a linear iterative procedure is adapted for trace gas retrievals in the other two algorithms. 
Table 2. Baseline DOAS analysis settings for the HONO fit.

\begin{tabular}{|c|c|}
\hline Parameter & Common setting \\
\hline Fitting spectral range & $335-373 \mathrm{~nm}$ \\
\hline Wavelength calibration & Calibration based on Fraunhofer lines of Kurucz solar spectrum (Kurucz et al., 1984) \\
\hline \multicolumn{2}{|l|}{ Cross sections } \\
\hline HONO & Stutz et al. (2000), $296 \mathrm{~K}$ \\
\hline $\mathrm{NO}_{2}$ & $\begin{array}{l}\text { Vandaele et al. (1998), } 220 \text { and } 298 \mathrm{~K}, \mathrm{I}_{0} \text {-corrected }\left(10^{17} \text { molec. } \mathrm{cm}^{-2}\right) \\
\text { Taylor terms (see Pukīte et al., 2010) with respect to } \sigma_{\mathrm{NO}_{2}} \text { at } 298 \mathrm{~K}: \lambda \sigma_{\mathrm{NO}_{2}}, \sigma_{\mathrm{NO}_{2}}^{2}\end{array}$ \\
\hline $\mathrm{O}_{3}$ & Bogumil et al. (2003), 223 and $243 \mathrm{~K}, \mathrm{I}_{0}$-corrected ${ }^{*}\left(10^{20}\right.$ molec. $\left.\mathrm{cm}^{-2}\right)$ \\
\hline $\mathrm{BrO}$ & Fleischmann et al. (2004), $223 \mathrm{~K}$ \\
\hline $\mathrm{O}_{4}$ & Thalman and Volkamer (2013), $293 \mathrm{~K}$ \\
\hline $\mathrm{HCHO}$ & Meller and Moortgat (2000), $297 \mathrm{~K}$ \\
\hline $\mathrm{H}_{2} \mathrm{O}$ (vapour) & Polyansky et al. (2016) scaled by 2.6 (Lampel el al., 2017) \\
\hline Ring effect & $\begin{array}{l}\text { Ring spectrum calculated based on Kurucz solar atlas and Ring scaled with } \\
(\lambda / 354 \mathrm{~nm})^{4} \text { (Wagner et al., 2009) }\end{array}$ \\
\hline Intensity offset & Polynomial of order 1 (corresponding to two coefficients) \\
\hline Polynomial term & Polynomial of order 5 (corresponding to six coefficients) \\
\hline Wavelength adjustment & All spectra are shifted and stretched against FRS \\
\hline Fraunhofer reference & 1. Daily noon FRS (at $11: 30$ ) \\
\hline Spectrum (FRS) & 2. Sequential FRS \\
\hline
\end{tabular}

Table 3. Common settings of the HONO profile retrievals.

\begin{tabular}{|c|c|}
\hline Parameter & Values \\
\hline Atmosphere definition & $\begin{array}{l}\text { Pressure, temperature, total air density, and } \mathrm{O}_{3} \text { vertical profiles } \\
\text { averaged from sonde measurements in De Bilt (Sep 2013-2015); surface albedo should } \\
\text { be fixed to } 0.06 \text {. }\end{array}$ \\
\hline Retrieval altitude grid & $\begin{array}{l}0-4 \mathrm{~km} \text { and step of } 200 \mathrm{~m} \text {. The surface height and instrument altitude are } \\
\text { fixed to } 0 \mathrm{~m} .\end{array}$ \\
\hline Wavelength & $\begin{array}{l}355 \mathrm{~nm} \text { (effective centre of the wavelength range }(335-373 \mathrm{~nm}) \text { of the HONO delta } \\
\text { SCD retrieval) }\end{array}$ \\
\hline Aerosol properties & $\begin{array}{l}\text { The single scattering albedo should be fixed to } 0.92 \text { and the asymmetry factor to } 0.68 \text {. } \\
\text { The aerosol profiles retrieved at } 360 \mathrm{~nm} \text { from } \mathrm{O}_{4} \text { can be directly used. }\end{array}$ \\
\hline Elevation angles & Those used in the measurement acquisition protocol: $1,2,3,4,5,6,8,15,30^{\circ}$ \\
\hline Measurement uncertainty covariance & $\begin{array}{l}\text { Squares of } 100 \% \text { of the SCD fit error for the diagonal terms and extra-diagonal terms } \\
\text { are zero. }\end{array}$ \\
\hline A priori profiles & $\begin{array}{l}\text { Exponentially decreasing profile derived using the VCD of } 3 \times 10^{14} \text { molec. } \mathrm{cm}^{-2} \text { and } \\
\text { a scaling height }(\mathrm{SH}) \text { value of } 0.1 \mathrm{~km}\end{array}$ \\
\hline A priori covariance matrices $(\mathrm{Sa})$ & $\begin{array}{l}\text { Squares of } 100 \% \text { of the a priori profile for the diagonal terms and } \\
\text { extra-diagonal terms are added as Gaussian functions with a correlation length of } \\
200 \mathrm{~m} \text {. }\end{array}$ \\
\hline
\end{tabular}




\subsubsection{Comparison scheme}

In order to attribute the discrepancies between the different data sets of HONO profiles to different possible causes (instrumental properties, FRS selection, profile inversion algorithms, and aerosol inversions), the inter-comparison of the HONO profiles is subdivided into four tasks named T1a, T1b, T2a, and T2b. In all four tasks, the HONO profiles are retrieved using different inversion algorithms by individual participants, while the differences between the tasks are the choices of the input HONO delta SCDs and aerosol profiles.

In tasks T1a and T1b, the input HONO delta SCDs are those retrieved from measurements of the individual instruments by the individual participants. Differently, in tasks $\mathrm{T} 2 \mathrm{a}$ and $\mathrm{T} 2 \mathrm{~b}$, different participants use the same HONO delta SCDs, which are retrieved from measurements of the "MPIC" instrument by "MPIC". Using different input delta SCDs allows investigation of whether the discrepancies of the HONO profiles are related to differences of HONO delta SCD retrievals or the profile inversion algorithms, respectively. For tasks T1a and T1b either the "sequential FRS" or the "daily noon FRS" was used in the DOAS fits, respectively, which allows us to quantify the effect of the FRS selections on the HONO profile retrievals. Tasks T2a and $\mathrm{T} 2 \mathrm{~b}$ differ with regard to the input profiles of aerosol extinction used for HONO profile inversion. In task T2a, different participants used the same aerosol profiles, which are retrieved from the $\mathrm{O}_{4}$ delta SCDs derived from the "MPIC" MAX-DOAS measurements using the "PriAM" algorithm by "MPIC". However, in task T2b, the input aerosols are retrieved from the $\mathrm{O}_{4}$ delta $\mathrm{SCDs}$, derived from the individual MAX-DOAS instruments by the respective participants. Using different input aerosol profiles allows quantification of the effects of aerosol retrievals on the consistency of the HONO profile retrievals. It should be noted that the input profiles of aerosol extinctions in tasks T1a, T1b, and T2b are the same and are derived from the aerosol profile retrievals at $360 \mathrm{~nm}$, as given in Tirpitz et al. (2020), using the common settings by the individual participants. In addition, since different measurement protocols are followed by 2D systems and $1 \mathrm{D}$ systems (see Sect. 2.2.2), only the coincident HONO measurements in the first 15 min of each hour are included in the comparison activities.

\subsubsection{Long-path DOAS measurements for comparisons with MAX-DOAS results}

A co-located long-path (LP-)DOAS instrument measured HONO concentrations near the surface using an artificial light source during the campaign. The telescope of the LPDOAS was installed west of the measurement site at a distance of $3800 \mathrm{~m}$. A detailed description of the instrumental set-up can be found elsewhere (Nasse et al., 2019). Four retro-reflector arrays were mounted at different heights $(15$, 45,105 , and $205 \mathrm{~m}$ ) at the Cabauw meteorological mea-
Table 4. LP-DOAS analysis settings.

\begin{tabular}{ll}
\hline Parameter & Common setting \\
\hline Fit range & 292.23-367.51 nm \\
$\mathrm{NO}_{2}$ & Burrows et al. (1998) \\
$\mathrm{O}_{3}$ & Serdyuchenko et al. (2014) \\
$\mathrm{HCHO}$ & Meller and Moortgat (2000), 297 K \\
$\mathrm{HONO}$ & Stutz et al. (2000), 296 K \\
$\mathrm{O}_{4}$ & Thalman and Volkamer (2013), 293 K \\
Lamp spectrum & From measurements \\
Background spectrum & From measurements \\
Polynomial & Degree 3 \\
\hline
\end{tabular}

surement tower close to the MAX-DOAS site. Consecutive measurements were performed on each retro-reflector, leading to a time resolution of approximately $15 \mathrm{~min}$. The measurements with the retro-reflector at the height of $205 \mathrm{~m}$ result in average HONO concentrations along the light path, which are compared with HONO concentrations in the lowest $200 \mathrm{~m}$ layer of profiles derived from MAX-DOAS measurements in Sect. 4.2.2 and 4.3.3. The DOAS fit settings for the retrievals of HONO are given in Table 4.

\subsubsection{Synthetic dSCDs for sensitivity analysis}

In most of the cases, the true HONO profiles are not known for real MAX-DOAS measurements, which makes it difficult to quantify biases of retrieved HONO profiles with respect to reality. In order to overcome this limitation, we generated a set of synthetic HONO delta SCDs using the RTM SCIATRAN, version 3.6.0 (3 December 2015) (Rozanov et al., 2014) assuming three different HONO profiles shown in Fig. 1a. The three HONO profiles represent scenarios with HONO accumulated near the surface (profile 1), linearly decreasing with altitude from the surface up to $0.8 \mathrm{~km}$ (profile 2), and a box-shaped profile with constant HONO VMRs in the altitude range from the surface up to $0.8 \mathrm{~km}$ and exponentially decreasing to zero above (profile 3 ). The HONO delta SCDs are simulated by the RTM at $355 \mathrm{~nm}$, according to the effective wavelength of HONO DOAS fits in a pseudo-spherical atmosphere with pure Rayleigh scattering (no clouds and aerosols) and with typical temperature and pressure profiles during the campaign. HONO is the only absorber included in the simulations, and the observation geometry is set according to the real measurements on 14 September 2016, during the CINDI-2 campaign. In order to test the effect of the measurement noise, we generated a modified data set by adding artificial random noise to the HONO delta SCDs simulated by the RTM with a signal-tonoise ratio of 3000, which was determined based on the typical noise level of most of the MAX-DOAS instruments in the study. One-hundred HONO delta SCDs were generated by adding noise to the individual simulated HONO delta SCDs. This modified data set of HONO delta SCDs with artificial 

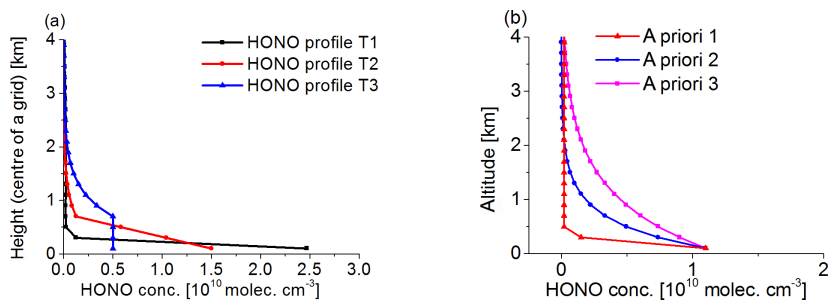

Figure 1. (a) Assumed HONO profiles used for the RTM simulations of the HONO delta SCDs. (b) Three different a priori profiles which were used for the sensitivity studies based on synthetic HONO delta SCDs.

noise is referred to as "noisy synthetic HONO delta SCDs" in the following (see Sect. 5.1). All the synthetic HONO delta SCDs are used in the sensitivity studies presented in Sect. 5.1. The profiles shown in Fig. $1 \mathrm{~b}$ are used as a priori profiles in the sensitivity studies.

\subsection{Cloud classification}

In order to evaluate the cloud effects on the MAX-DOAS results and their consistency, the cloud classification scheme described in Wang et al. (2015) and Wagner et al. (2014, 2016) was applied to the MPIC MAX-DOAS measurements during the whole CINDI-2 campaign. The sky conditions are identified from the colour index (ratio of intensities at 330 and $390 \mathrm{~nm}$ ) and the $\mathrm{O}_{4}$ dSCDs (retrieved in the spectral range of 338-370 nm) derived from MAX-DOAS measurements of individual elevation sequences. From the classification scheme, six categories are identified, including (a) "cloud free and low aerosol load", (b) "cloud free and high aerosol load", (c) "cloud holes", (d) "broken clouds", (e) "continuous clouds", and (f) "optically thick clouds". Here, the difference between categories (c) and (d) is given by the general optical thickness: it is larger for "broken clouds" than for "cloud holes". In order to simplify the comparison activities, the categories of "cloud free and low aerosol load" and "cloud free and high aerosol load" are combined and treated as "clear sky" in this study. The remaining categories, except "optically thick clouds", are treated as "cloudy sky". It should be noted that the results for the category "optically thick clouds" are not included in the comparisons because the HONO retrieval quantity is usually strongly degraded for such conditions (Wang et al., 2017b).

\section{Results of inter-comparison of tropospheric HONO dSCDs}

In this section we present the inter-comparison of $\mathrm{HONO}$ delta SCDs derived by the individual participants from their MAX-DOAS measurements using the baseline settings of the DOAS fits (see Sect. 2.2). The overview of the results of the HONO delta SCDs is presented in Sect. 3.1. The overall statistics of the inter-comparisons and the comparison results for the individual participants are discussed in Sect. 3.1 and 3.2 , respectively.

\subsection{Overview of tropospheric HONO delta SCDs during the CINDI-2 campaign}

For the comparison of the HONO delta SCDs, median values are calculated from the HONO delta SCDs derived from all participants for individual elevation angles separately for the HONO delta SCDs retrieved using the "sequential FRS" and the "daily noon FRS", respectively. The time series of median delta SCDs using the "sequential FRS" are shown in the top panel of Fig. 2a for the time interval of 06:00 to 17:00 UTC on the individual days of the campaign. The corresponding sky conditions identified from the MPIC MAXDOAS measurements (see Sect. 2.4) are given in the bottom panel of Fig. 2a. The sky condition results indicate that the frequencies of the "clear-sky" and "cloudy-sky" conditions are almost equal during the whole campaign. The peak values of the HONO delta SCDs typically appear in the early morning, except 27 September, when the peak value of $\sim 3 \times 10^{15}$ molec. $\mathrm{cm}^{-2}$ is found between 08:00 and 10:00 UTC. The peak values in the early morning reach values up to $\sim 8 \times 10^{15}$ molec. $\mathrm{cm}^{-2}$, as e.g. observed on 21 and 22 September. A large spread of HONO delta SCDs along the elevation angles can be seen and usually with maximum values typically at a $1^{\circ}$ elevation angle.

\subsection{Statistical inter-comparisons of HONO delta SCDs}

For the results using the "sequential FRS", median diurnal variations for individual elevation angles of all data sets from all participants are calculated and shown in Fig. 2b. Note that the median values are calculated over both measurement time and all instruments. HONO delta SCDs strongly decrease with increasing elevation angles, especially in the morning, and the spread of the HONO delta SCDs along elevation angles decreases steeply during the day. At 06:00 UTC the HONO delta SCDs are $\sim 3.2 \times 10^{15}$ molec. $\mathrm{cm}^{-2}$ and $\sim 0.2 \times 10^{15}$ molec. cm ${ }^{-2}$ for elevation angles of 1 and $30^{\circ}$, respectively. During the day, a continuous decrease in the HONO delta SCDs for elevation angles of $1^{\circ}$ is seen, with the strongest decrease from $\sim 3.2 \times 10^{15}$ to $\sim 1.2 \times$ $10^{15}$ molec. $\mathrm{cm}^{-2}$ between 06:00 and 08:00 UTC. For the high elevation angles, the change is much smaller. For instance, the HONO delta SCDs are $\sim 0.2 \times 10^{15}$ molec. $\mathrm{cm}^{-2}$ at the elevation angles of $30^{\circ}$ during the whole day.

In order to evaluate the agreement of the HONO delta SCDs between the different participants, for the same data sets, the diurnal variation of the standard deviation of all HONO delta SCDs compared to the median values as shown in Fig. 2a is calculated and shown in Fig. 2c. Note that temporal variations of HONO delta SCDs do not impact the standard deviations because the median values in the indi- 


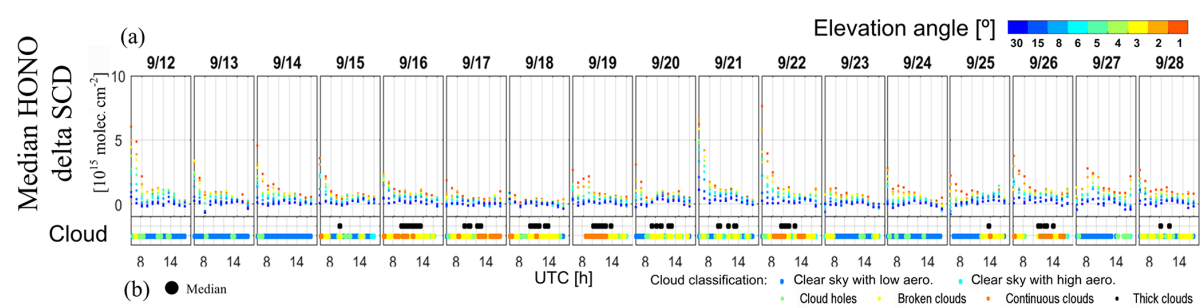

(b) Median
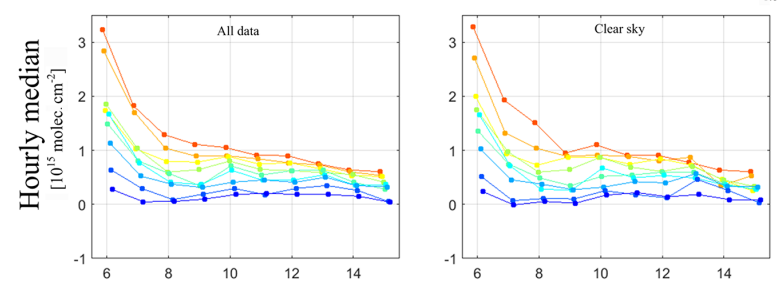

, Broles
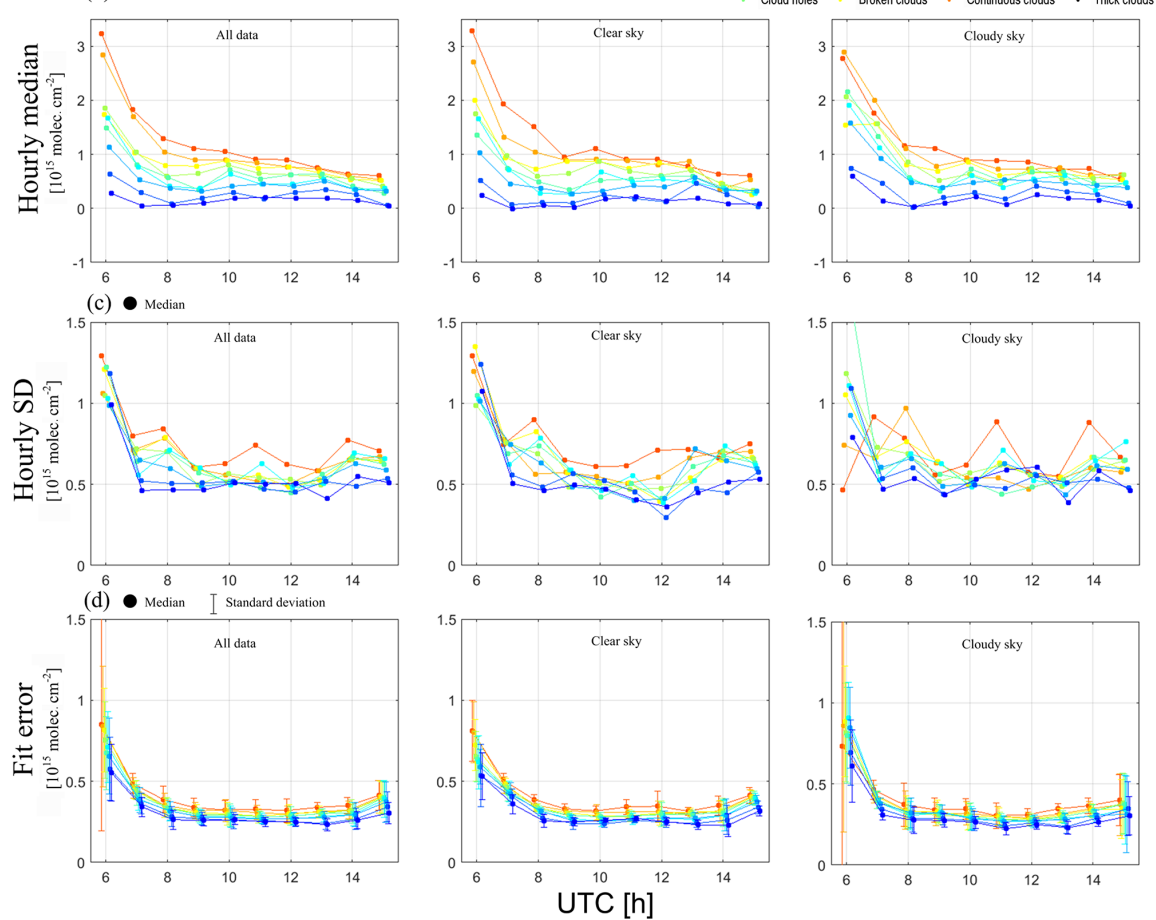

Figure 2. Overview of the HONO delta SCDs retrieved from all MAX-DOAS instruments using the "sequential FRS" during the whole CINDI-2 campaign period. (a) Time series of median HONO delta SCDs derived from measurements of all MAX-DOAS instruments by individual groups. The results of the cloud classification algorithm (applied to the "MPIC" measurements) are shown at the bottom of the subfigures. The colours indicate the elevation angles and cloud categories, respectively. The colours in (b), (c), and (d) indicate elevation angles as shown in the upper panel of (a). (b) Diurnal variations of hourly median HONO delta SCDs derived from all MAXDOAS instruments. (c) Diurnal variation of hourly standard deviations of differences from median HONO delta SCDs from all MAX-DOAS instruments. (d) Hourly median and standard deviations of the DOAS fit errors of the HONO delta SCDs from all MAX-DOAS instruments. The left, centre, and right columns of subfigures represent the results for all the data as well as results for "clear-sky" and "cloudy-sky" conditions, respectively.

vidual time steps shown in Fig. 2a served as a reference in the calculations. The standard deviation is much larger in the early morning $\left(\sim 1.2 \times 10^{15}\right.$ molec. $\left.\mathrm{cm}^{-2}\right)$ at 06:00 UTC than those at a later time. The standard deviations are slightly larger at low elevation angles than those at high elevation angles. Compared to the median values of the HONO delta SCDs, the relative standard deviation is much smaller at low elevation angles (e.g. $40 \%-100 \%$ at $1^{\circ}$ elevation angle) than at high elevation angles (e.g. $200 \%-400 \%$ at $30^{\circ}$ elevation angle). Similarly, the relative standard deviation in the afternoon is much larger than that in the early morning, e.g. $40 \%$ at 06:00 UTC and $100 \%$ at 15:00 UTC, consistent with lower daytime HONO concentrations (and thus larger relative measurement errors) at the measurement site. Since the DOAS fit errors indicate the uncertainties of the DOAS retrieval of the HONO delta SCDs, the diurnal variation of the median and standard deviation of the fit errors of all the data sets is also shown in Fig. 2d. As demonstrated for other trace gas species in Kreher et al. (2019), the DOAS fit errors and standard deviations of HONO delta SCDs should be comparable under ideal conditions, which means different instruments measuring with exactly the same field of view (FOV) and acquisition time under stable atmospheric conditions. However, those ideal conditions can not be perfectly reached in reality. By comparing Fig. 2c and d, one can see that the fit errors are smaller than the standard deviation of the HONO delta SCDs by $\sim 0.3 \times 10^{15}$ molec. $\mathrm{cm}^{-2}$, i.e. by about $50 \%$. This feature indicates that the effects of atmospheric variability in 
the FOV of $\sim 1^{\circ}$ (corresponding to a round sky area with a radius of $\sim 100 \mathrm{~m}$ under a frequent maximum visible distance of $\sim 10 \mathrm{~km}$ ) and discrepancies of FOV and acquisition time between the different instruments can considerably contribute to random discrepancies of HONO delta SCD measurements. A similar conclusion was obtained in the previous studies of Kreher et al. (2019) and Bösch et al. (2018). The differences of random discrepancies and DOAS fit errors depend on actual instrumental noise levels, measured species, and atmospheric variability conditions. Regarding the dependence on measured species, Kreher et al. (2019) reported that random discrepancies of $\mathrm{NO}_{2}$ dSCDs in the visible range are larger than DOAS fit errors by an order of magnitude. Comparisons of DOAS fit errors and random discrepancies of HONO delta SCDs will be discussed for individual instruments in Sect. 3.3.1.

In order to evaluate the effect of clouds on the consistency of the HONO delta SCDs between the different data sets, we show the diurnal variation of the median values of the HONO delta SCDs, corresponding standard deviations, and the median and standard deviations of the DOAS fit errors separately calculated for measurements under "clear-sky" and "cloudy-sky" conditions (see Sect. 2.4 about the cloud classification) in Fig. 2. In general, similar values of all the quantities are found for both sky conditions, probably due to the fact that HONO abundances are mostly near ground level and HONO absorption light paths are not considerably affected by clouds located at high altitudes. However, for the standard deviation of the HONO delta SCDs, larger values are found under "cloudy-sky" conditions than under "clearsky" conditions. The standard deviation of the DOAS fit error under "cloudy-sky" conditions is larger than under "clearsky" conditions. This finding might be attributed to two factors: (1) the rapid variation of cloud properties for conditions of inhomogeneous cloud coverage; (2) the enhanced photon shot noise, due to the fact that fewer photons are received by instruments under "cloudy-sky" conditions, can result in larger random noise and further larger discrepancies of HONO delta SCDs between different instruments compared to those under "clear-sky" conditions. Wagner et al. (2014) demonstrated that the number of photons (proportional to measured radiance) is typically reduced by more than $10 \%$ under optically thick clouds compared to those under clearsky conditions. In addition, results similar to that shown in Fig. 2 are also observed for the data sets retrieved using the "daily noon FRS". Hence, we only show the results of using the "sequential FRS".

\subsection{Comparison results for individual participants}

For the data sets of HONO delta SCDs from individual participants, linear regressions against the median values are calculated for the whole campaign. The corresponding correlation coefficients, slopes, intercepts, and root mean square (rms) of the residuals are shown in Fig. 3a, b, c, and d, respec- tively. The corresponding median values and standard deviations are presented in Fig. 3e. The median values and standard deviations of the DOAS fit error are shown in Fig. 3f. For the intercepts, rms, median differences, and fit errors shown in Fig. 3d, e, and f, a second $y$ scale is added on the right-hand side of the diagrams. It indicates the typical relative discrepancy compared to a typical high value of the HONO delta SCDs of $2 \times 10^{15}$ molec. $\mathrm{cm}^{-2}$. This quantity is referred to as the "typical percentage" in the subsequent part of this section. Since the HONO profile retrievals are dominated by measurements at low elevation angles, the comparison results for $1^{\circ}$ elevation are separately plotted in Fig. 3 (red and green dots). Also, the comparison results for analyses using a "sequential FRS" or "daily noon FRS" are individually presented.

The discrepancies of the HONO delta SCDs between the different MAX-DOAS instruments consist of random and systematic discrepancies. The random discrepancies can be minimized by averaging over a large number of measurements since instrumental noise and spatial-temporal variations of sky conditions and pollutants can be smoothed out by the averaging. The effect has been studied in Peters et al. (2019). In Fig. 3d, the rms values of residuals of linear regressions against the median values can represent the random measurement errors similarly to the standard deviations of HONO delta SCDs discussed in Sect. 3.2, whereas the slopes, intercepts, and median differences shown in Fig. 3b, $\mathrm{c}$, and e indicate the systematic discrepancies. For comparisons with the rms values, the DOAS fit errors from individual participants are also shown in Fig. $3 \mathrm{f}$.

\subsubsection{Random discrepancies}

The rms values shown in Fig. 3d for HONO delta SCDs are lower than $\sim 0.6 \times 10^{15}$ molec. $\mathrm{cm}^{-2}$ for most of the participants, corresponding to a "typical percentage" of $30 \%$. The rms values obtained using a "sequential" FRS and a "daily noon FRS" are similar in magnitude for most of the participants if all elevation angles or only the $1^{\circ}$ elevation angle are considered. The lowest rms values of $\sim$ $0.3 \times 10^{15}$ molec. $\mathrm{cm}^{-2}$, corresponding to a "typical percentage" of $15 \%$, are reached by the "BIRA", "NIWA (2)", "AMOIAP", and "NIWA (1)" instruments. Even though the "NIWA (1)" instrument belongs to the group of "EnviMes" instruments, a lower rms is reached by the "NIWA (1)" instrument compared to the other "EnviMes" instruments. The improved performance might be attributed to the customized productions and personalized operation of the individual "EnviMes" instruments as well as different implementations of the DOAS fits by the individual participants. Another interesting finding for the "EnviMes" instruments is that although the same set of spectra measured by the "USTC" instruments (see Table 1) is analysed by the "DLR" and "USTC" researchers, much larger rms values and fit errors are found for the "DLR(1)" and "DLR(2)" results (es- 


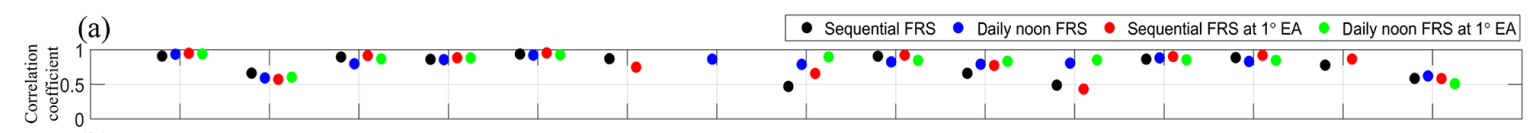

(b)
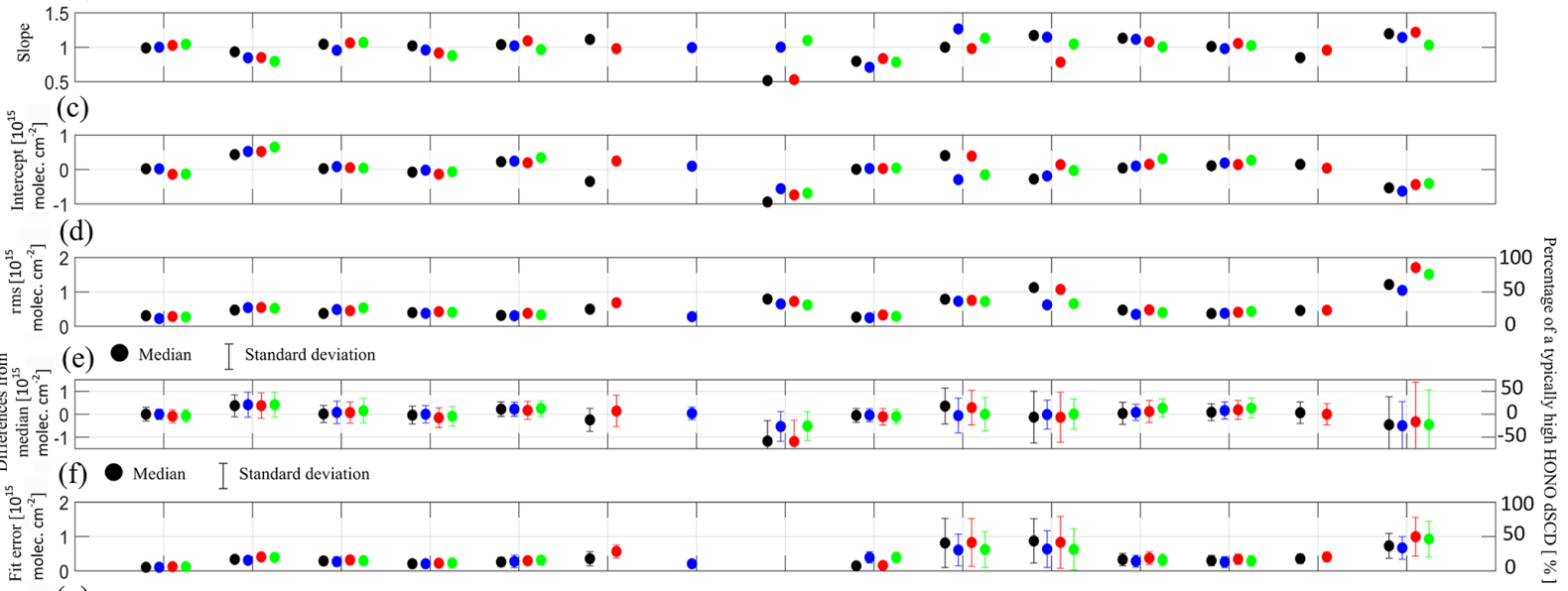

(g)

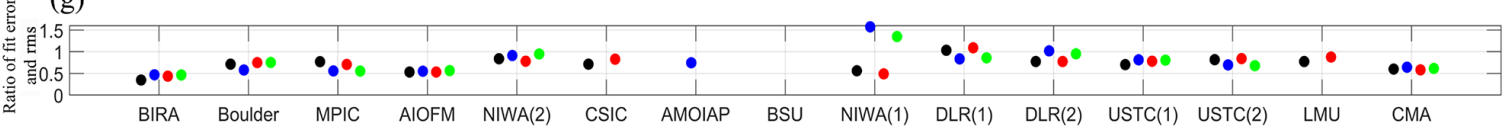

Instrument

Figure 3. Correlation coefficients (a), slopes (b), intercepts (c), and rms of the residuals (d) derived from the linear regressions versus the median values. The median differences and standard deviations derived from the comparison of the HONO delta SCDs from individual instruments and the median values of all instruments during the whole CINDI-2 campaign period are shown in (e). In (f) the median values and the standard deviation of the DOAS fit error are shown. The $y$ axis on the right-hand side of (d), (e), and (f) indicates percentages calculated by dividing the absolute errors by a typical high HONO delta SCD of $2 \times 10^{15}$ molec. $\mathrm{cm}^{-2}$. In (g) ratios of rms and DOAS fit errors are shown.

pecially for the "DLR(2)" results with the "sequential FRS") than for the "USTC(1)" and "USTC(2)". This finding implies that random discrepancies between the data sets can be considerably attributed to the specific implementation of the DOAS fits and the characteristics of the instrumental slit functions by the individual participants. The previous study of Peters et al. (2017) demonstrated that differences in DOAS retrieval codes can result in discrepancies of retrieved $\mathrm{NO}_{2}$ dSCDs and rms residuals by up to $8 \%$ and $100 \%$, respectively. Since optical depths of HONO absorptions are typically much lower than $\mathrm{NO}_{2}$, the effect of differences in DOAS retrieval codes and DOAS implementations by individual participants on retrieved HONO dSCDs might be relatively larger than that on $\mathrm{NO}_{2}$. The "CMA" rms values derived for a Hoffmann Mini-DOAS instrument are the largest ( $\sim 1$ to $1.7 \times 10^{15}$ molec. $\mathrm{cm}^{-2}$, corresponding to a "typical percentage" of $30 \%$ to $85 \%$ ). The large rms of "CMA" is consistent with its large fit error of $\sim 1 \times 10^{15}$ molec. $\mathrm{cm}^{-2}$. Therefore, we conclude that the Hoffmann Mini-DOAS instruments can hardly reach the signal-to-noise requirements for HONO measurements in cases of HONO dSCDs lower than $\sim 2 \times 10^{15}$ molec. $\mathrm{cm}^{-2}$.

Figure $3 \mathrm{~g}$ shows the ratios of DOAS fit errors and the rms values for individual data sets. This relates to the discussion at the end of Sect. 3.2 on the differences of DOAS fit errors and random discrepancies. Fig. $3 \mathrm{~g}$ indicates that the ratios are different for different data sets and in the range of 0.3 to 1.6. For most of the data sets, the ratios are lower than unity, indicating that effects of atmospheric variability and discrepancies of instrumental FOV and acquisition time dominate random discrepancies more than the effect of instrumental noise given by DOAS fit errors. The lowest ratio of 0.3 is found for the "BIRA" data set. It indicates that the dominant factors of the random discrepancies of the "BIRA" data set are atmospheric variability and instrumental discrepancies, but not instrumental noise.

\subsubsection{Systematic discrepancies}

For an overview of the systematic biases, median differences of the individual data sets of HONO delta SCDs from the median values are calculated and shown in Fig. 3e. These biases are mostly in the range of $\pm 0.3 \times 10^{15}$ molec. $\mathrm{cm}^{-2}$, corresponding to a "typical percentage" of about $\pm 15 \%$. The slopes derived from the linear regression mostly deviate from unity by about $\pm 20 \%$ and the intercepts are mostly in the range of $\pm 0.3 \times 10^{15}$ molec. $\mathrm{cm}^{-2}$, which corresponds to a "typical percentage" of about $\pm 15 \%$. For the individual data sets, the median differences are generally consis- 
tent with the intercepts but not the slopes. This finding is related to the fact that low and high HONO delta SCDs dominate the intercept and slope derived from the linear regression. Since low values are more frequent than large values, the median values of the differences are dominated by the lower HONO delta SCDs. Hence the intercepts and slopes mainly represent the systematic discrepancies of low and high values of the HONO delta SCDs, respectively, whereas the median differences indicate the general bias. For the data sets from "BIRA","MPIC", "AIOFM", "NIWA (2)", "AMOIAP", "USTC (1)", "USTC (2)", and "LMU", the median differences, slopes, and intercepts are all in the range of $\pm 0.3 \times 10^{15}$ molec. $\mathrm{cm}^{-2}, \pm 20 \%$ deviation from unity, and $\pm 0.3 \times 10^{15}$ molec. $\mathrm{cm}^{-2}$, respectively, representing the corresponding typical ranges. Much larger biases of the slopes $(\sim 0.5)$ are found for the "BSU" data with "sequential FRS" than that for those with "daily noon FRS". The reason for this finding is not yet identified. For the "DLR (1)" and "DLR (2)" data, although the median differences fall within the range of typical values, different biases (about plus $30 \%$ or minus $30 \%$ for large HONO delta SCDs, as indicated by the slopes) are found for "DLR (1)" with "daily noon FRS" and the "DLR (2)" with the "sequential FRS" at $1^{\circ}$ elevation angle, respectively. Considering that the "DLR" data are derived from the same set of spectra as the "USTC" data, the different implementations of the DOAS fits by both participants might have caused the different results. For the "CMA" data sets, although the deviations of the slopes from unity are within about $20 \%$, the median differences and intercepts of about $-0.5 \times 10^{15}$ molec. $\mathrm{cm}^{-2}$ indicate a larger underestimation of low HONO delta SCDs than for the other participants. However, here it should be noted that the correlation coefficient is also rather low $(r \sim 0.6)$.

In order to further characterize the diurnal variation of the discrepancies for the individual participants, the median and 25th and 75th percentiles of the differences of the HONO delta SCDs from the medians for elevation angles of $1^{\circ}$, $5^{\circ}$, and $15^{\circ}$, respectively, are shown in Fig. 4. The comparison results for the data sets with "sequential FRS" and "daily noon FRS" are shown in subpanels a and b. Considerable diurnal variations of the discrepancies are found for the "DLR", "BSU", and "CMA" data. For "DLR" data, negative and positive biases usually occur in the early morning and around noon, respectively, especially if a "sequential FRS" is used. Larger negative biases in the morning and in the afternoon are observed for "CMA". Larger negative biases of the "BSU" data with "sequential FRS" appear in the morning, whereas the "BSU" data with "daily noon FRS" show larger negative biases around noon. Additionally, different biases for different elevation angles are found for some data. For instance, the discrepancies of the "AIOFM", "NIWA (2)", and "USTC (2)" data are larger for the $1^{\circ}$ elevation angle than for other elevation angles in the early morning.

In order to evaluate the effects of the FRS selection on the HONO delta SCDs, the median and percentiles of the dif- ferences of the HONO delta SCDs of both procedures are shown in Fig. 4c. The statistics of the differences are provided for different hours of the day and elevation angles of $1^{\circ}, 5^{\circ}$, and $15^{\circ}$, respectively. For most of the data sets, including "BIRA", "MPIC", "Boulder", "AIOFM", "NIWA (2)", "NIWA(1)", "USTC (1)", and "USTC (2)", the median values of the differences are usually in the range of $\pm 0.1 \times$ $10^{15}$ molec. $\mathrm{cm}^{-2}$ (corresponding to a "typical percentage" of $5 \%$ ), while the 25 th and 75 th percentiles are in the range of $0.2 \times 10^{15}$ molec. $\mathrm{cm}^{-2}$ (corresponding to a "typical percentage" of $10 \%)$. For the "BSU" data, a large positive bias of $\sim 3 \times 10^{15}$ molec. $\mathrm{cm}^{-2}$ is found in the early morning and decreases afterwards. The reason for this finding is not yet identified. The median differences for both "DLR" data sets are in the range of $\pm 1.6 \times 10^{15}$ molec. $\mathrm{cm}^{-2}$ (corresponding to a "typical percentage" of $\sim \pm 80 \%$ ), depending on the time of a day, whereas the differences of the 25 th and 75 th percentiles are about $1 \times 10^{15}$ molec. $\mathrm{cm}^{-2}$. However, considering the fact that both the "DLR" and "USTC" data sets are derived from the same spectra, we conclude that the different effects of the FRS selection arise from the specific implementations of DOAS fits. For the "CMA" data, the median differences are in the range of 0.2 to $-0.4 \times 10^{15}$ molec. $\mathrm{cm}^{-2}$. This finding probably reflects the effects of instrumental instability.

In general, for most of the instruments with moderate performance during this campaign, systematic discrepancies between the data sets are in the range of $\pm 0.3 \times$ $10^{15}$ molec. $\mathrm{cm}^{-2}$, which is about half of the general random discrepancy of $\sim \pm 0.6 \times 10^{15}$ molec. $\mathrm{cm}^{-2}$. For a typical high HONO delta SCD of $2 \times 10^{15}$ molec., $\mathrm{cm}^{-2}$, the typical relative systematic and random discrepancies are about $15 \%$ and $30 \%$, respectively. The lowest random discrepancy of $\sim 0.3 \times 10^{15}$ molec. $\mathrm{cm}^{-2}$, which is comparable to the general systematic bias, can be reached by some instruments. For some data sets, the systematic differences are higher (up to $\pm 0.5 \times 10^{15}$ molec. $\mathrm{cm}^{-2}$ ), probably due to an inappropriate implementation of the DOAS fit. For most instruments, the FRS selection is not critical, as the systematic differences between the HONO delta SCDs retrieved using the "sequential FRS" or "daily noon FRS" are typically in the range of $\pm 0.1 \times 10^{15}$ molec. $\mathrm{cm}^{-2}$.

\subsubsection{Discussion on effects of misalignments of elevation angles}

Misalignments of elevation angles for individual instruments might result in discrepancies of HONO delta SCDs between the instruments. Since elevation misalignments might consist of systematic offsets and temporal changes for individual instruments, the resulting discrepancies in HONO delta SCDs might be both systematic and random. We estimated the typical bias of HONO delta SCDs according to a typical misalignment of elevation angles during the CINDI-2 campaign. Donner et al. (2019) characterized biases of elevation 


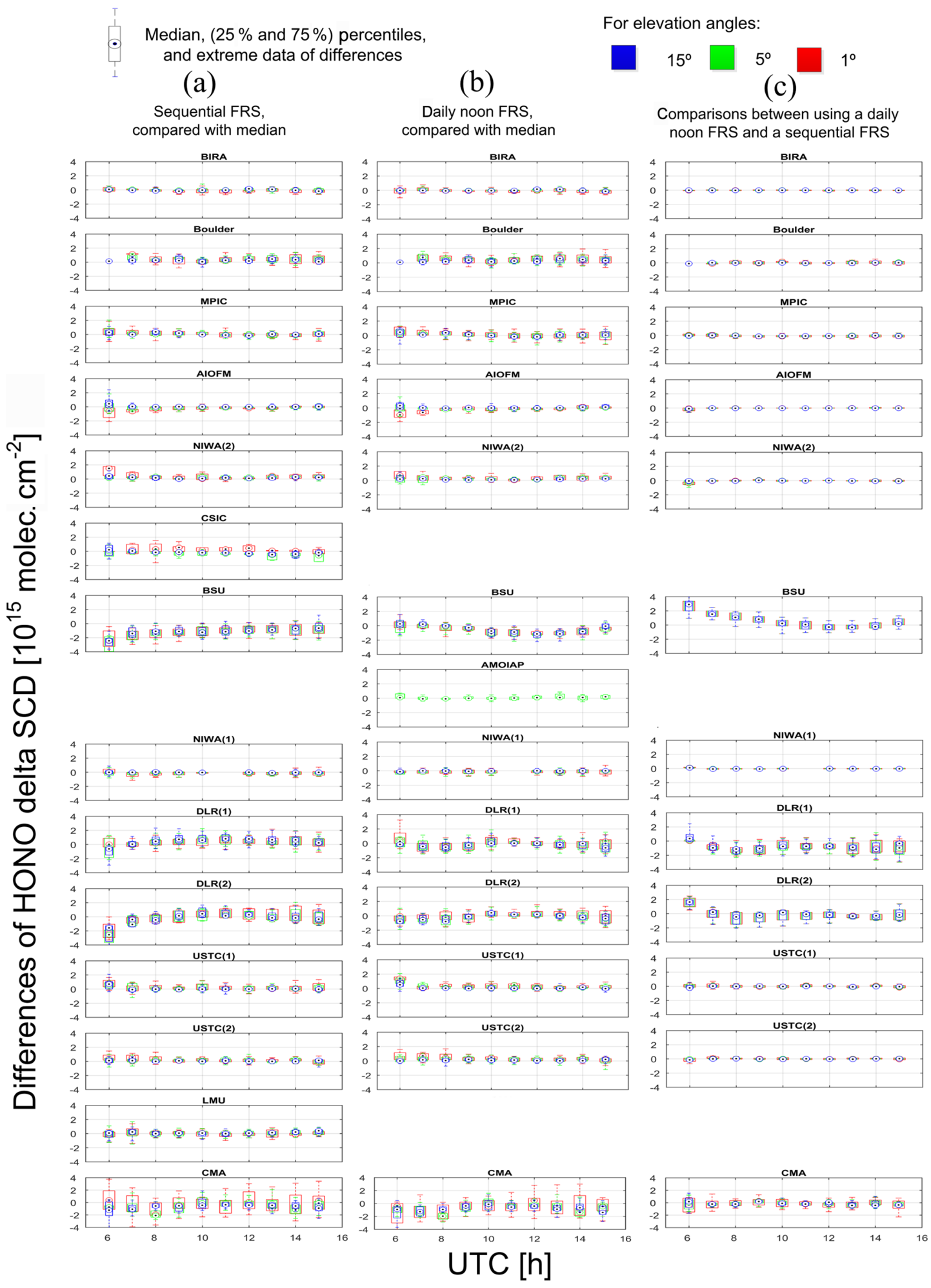

Figure 4. Boxplots (including median, percentiles, and extreme data) of the differences of the HONO delta SCDs for individual instruments (one instrument each row) with respect to the median values for the results using a "sequential FRS" (a) or a "daily noon FRS" (b). In the (c) column of subplots, the differences of the HONO delta SCDs for the results using a "sequential FRS" or "daily noon FRS" are shown for the individual instruments. Colours indicate the elevation angles. The gaps between the subplots are due to unavailability of the corresponding data. 
angles as mostly smaller than $0.4^{\circ}$ for most of the MAXDOAS instruments during the CINDI-2 campaign, based on scanning horizon and active light calibration methods applied to individual instruments. Figure $2 b$ indicates that the largest change in HONO delta SCDs per elevation angle degree appears at the lowest elevation angles of $1^{\circ}$ to $3^{\circ}$. Therefore, effects of misalignments of elevation angles on measured HONO delta SCDs are stronger at smaller elevation angles than at larger ones. Based on the typical dependence of HONO delta SCDs on elevation angles, the biases of HONO delta SCDs at $1^{\circ}$ due to a typical elevation angle bias of $0.4^{\circ}$ can be roughly estimated as $\sim 0.2 \times 10^{15}$ molec. $\mathrm{cm}^{-2}$ in the morning and $\sim 0.04 \times 10^{15}$ molec. $\mathrm{cm}^{-2}$ around noon, which are only a third of typical DOAS fit errors shown in Fig. $2 \mathrm{~d}$ and $\sim 10 \%$ of typical random discrepancies shown in Fig. 2b. Furthermore, we do not observe correlation between the bias of HONO delta SCDs from the median values and identified misalignments of elevation angles for some instruments, for which considerable elevation misalignments occurred during the campaign. Overall, the misalignments of elevation angles result in negligible discrepancies of HONO delta SCDs between the instruments.

\section{Inter-comparison of tropospheric HONO vertical profiles}

In this section we present the inter-comparison of vertical profiles of the HONO VMRs retrieved by the different participants with different inversion algorithms for the baseline retrieval settings (see Sect. 2.3.1). An overview of the retrieved profiles is presented in Sect. 4.1. The overall statistics and comparison results for the individual participants are given in Sect. 4.2 and 4.3, respectively.

\subsection{Overview of retrieved HONO profiles}

Time series of the HONO profiles retrieved by the different participants between 06:00 and 17:00 UTC on individual days during the whole campaign are plotted in Fig. 5 . This also includes all the profile results for the four comparison tasks described in Sect. 2.3.2. Although the HONO profiles were retrieved in the altitude range below $4 \mathrm{~km}$, only the results below $1 \mathrm{~km}$ are shown, because above $1 \mathrm{~km}$ only very small HONO mixing ratios are retrieved. However, for the calculation and inter-comparison of the HONO VCDs (Sect. 4.2 and 4.3), the HONO profiles are integrated for the altitude range from 0 to $4 \mathrm{~km}$. For the individual comparison tasks, the median values of the HONO profiles are calculated and also plotted in Fig. 5. All data sets indicate that HONO usually accumulates near the surface. However, considerable discrepancies in the absolute values and diurnal variations can also be seen. The sky conditions identified from the MPIC MAX-DOAS measurements (see Sect. 2.4) are shown in the bottom panel of Fig. 5. The gaps of results in Fig. 5 are due to the unavailability of data as the corresponding MAX-DOAS instruments were not operational or the profile inversion failed. For task T2b, the "MPIC (MAPA valid)" data show many more gaps than the "MPIC (MAPA)" data since the quality flag criteria (Beirle et al., 2019) were applied to the "MPIC (MAPA valid)" data. For tasks T1a and T1b, two versions of "BIRA" profile results are displayed and marked as "BIRA (v1)" and "BIRA (v2)" and discussed in Sect. 5.3. Since the "BIRA (v2)" data set is retrieved with more realistic measurement uncertainties than "BIRA (v1)", it has been decided to only use the "BIRA (v2)" data set in the further inter-comparison analysis in Sect. 4.2 and 4.3.

\subsection{Statistical inter-comparisons of HONO profiles, VCDs, and near-surface VMRs}

\subsubsection{Comparisons with median values}

The diurnal variations of the median values of the HONO VCDs and near-surface VMRs for all the data sets are calculated for the individual tasks and plotted in Fig. $6 a$ and b, respectively. A steep decrease in the HONO VCDs and nearsurface VMRs from $\sim 3$ to $\sim 1.5 \times 10^{14}$ molec. $\mathrm{cm}^{-2}$ and from $\sim 0.4$ to $\sim 0.1 \mathrm{ppb}$ between 06:00 and 08:00 UTC is found, respectively. Afterwards, the VCDs and VMRs close to the surface stay at low values, with a slight decrease until 16:00 UTC. Considering the significant decrease in HONO in the early morning, the median values of the HONO profiles before and after 07:00 UTC are separately shown in Fig. 6d and e, respectively. Both figures indicate that the HONO VMRs above $0.6 \mathrm{~km}$ are close to zero. In addition, Fig. $6 \mathrm{a}$ and $\mathrm{b}$ indicate considerable differences in the median values of the different tasks, especially in the early morning before 08:00 UTC. These differences can primarily be attributed to differences in the input HONO delta SCDs and aerosol profiles used in the profile retrievals.

The 25th and 75th percentiles of the differences of the HONO VCDs, near-surface VMRs, and vertical profiles before and after 07:00 UTC compared to the median values are shown in Fig. 6a, b, d, and e, respectively, with different columns indicating the four tasks. The deviations between the different data sets are much smaller if the common HONO delta SCDs (tasks T2a and T2b) are used than if the HONO delta SCDs measured by individual instruments (tasks T1a and T1b) were used. For task T2a, the half interquartile range is mostly $\sim 5 \times 10^{13}$ molec. $\mathrm{cm}^{-2}$ (corresponding to $\sim 15 \%$ to $\sim 30 \%$ of the median values) for the VCDs and $\sim 0.02 \mathrm{ppb}$ for the near-surface VMRs $(\sim 5 \%$ to $\sim 20 \%$ of the median values). For task T1a, the half interquartile range increased by about 3 times compared to those for task T2a. Therefore, we conclude that the discrepancies of the HONO delta SCDs can contribute $\sim 30 \%$ to $60 \%$ deviations of the HONO VCDs and $\sim 10 \%$ to $40 \%$ deviations of the near-surface VMR results. The deviations are smaller than the typical relative deviations of HONO 


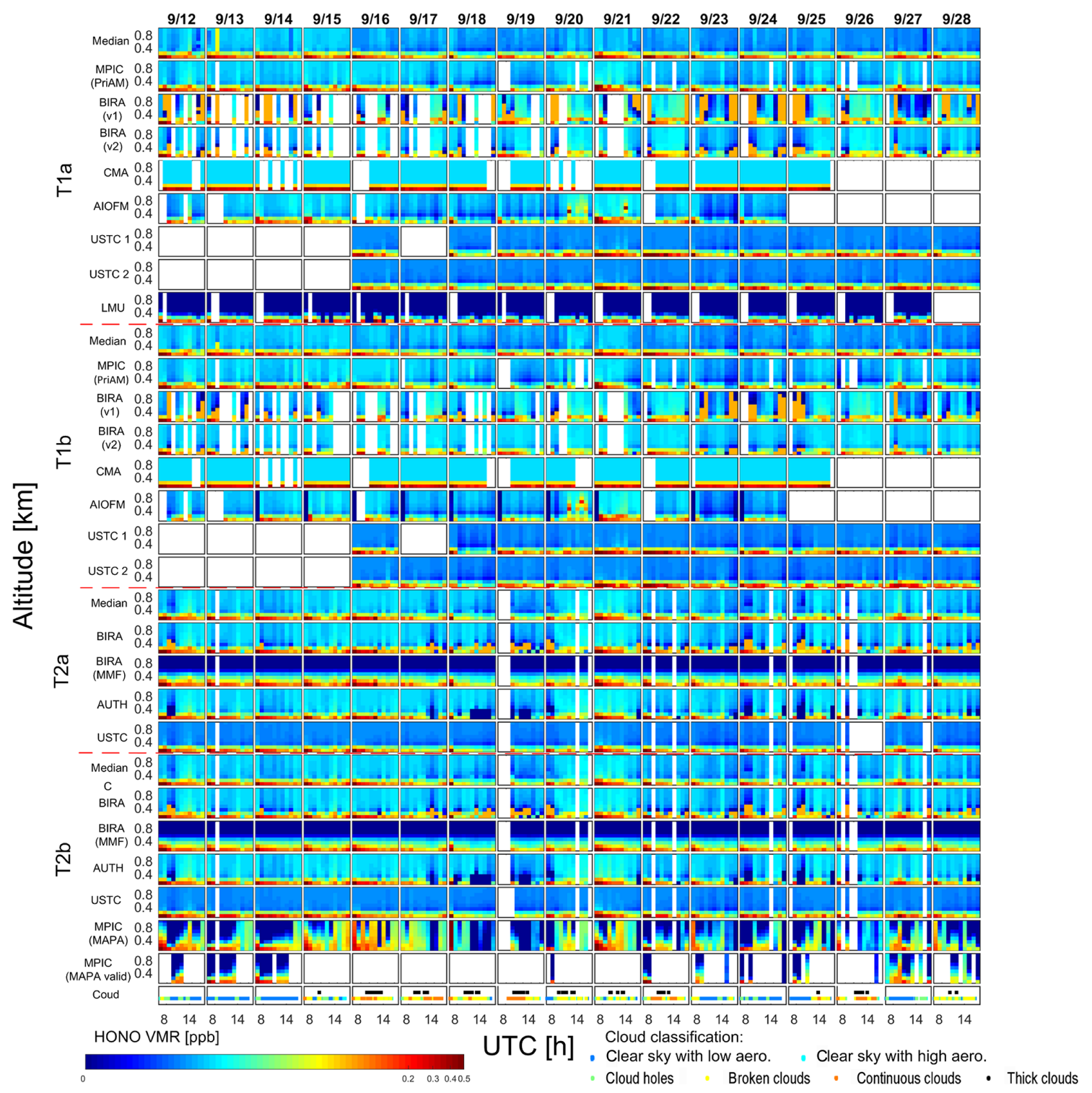

Figure 5. Overview of the time series of HONO profiles derived by different institutes and instruments for the four tasks. The median values for the individual tasks are also given. The colour map is given in logarithmic scale in order to show fine structures of low HONO VMR values above the surface. Note that the colour map starts from zero. Negative values can appear in some data sets but are generally insignificant since their mean values are about $-0.007 \mathrm{ppb}$. The cloud classification results are shown in the small subfigures at the bottom.

delta SCDs of $40 \%-100 \%$ at low elevation angles, which arise due to the smoothing effect of the profile inversion. For both tasks T2a and T2b, the absolute deviations are larger in the morning than in the afternoon, but the relative deviations are similar due to larger HONO values in the morning. Also, slightly larger interquartile ranges are found for task $\mathrm{T} 2 \mathrm{~b}$ than for task $\mathrm{T} 2 \mathrm{a}$, especially in the morning by $\sim 3 \times 10^{13}$ molec. $\mathrm{cm}^{-2}$ and $\sim 0.04 \mathrm{ppb}$, respectively. This indicates that the discrepancies of the aerosol retrievals can cause discrepancies of the HONO VCDs and near-surface VMRs by $\sim 50 \%$. Similar ranges of percentiles are found for tasks T1a and T1b, indicating that the effects of using either a "sequential FRS" or "daily noon FRS" on the consistency of the HONO profile retrievals are not critical. The comparison results of HONO profiles shown in Fig. 6d and e indicate that deviations of the HONO VMRs between different data sets are negligible at altitudes above $0.4 \mathrm{~km}$, where the HONO VMRs are also almost zero.

\subsubsection{Comparisons with LP-DOAS}

The statistical differences (the median values and 25th and 75th percentiles) of the near-surface HONO VMRs of the different data sets compared to the co-located LP-DOAS are shown in Fig. 6c. The LP-DOAS measurements and data for 


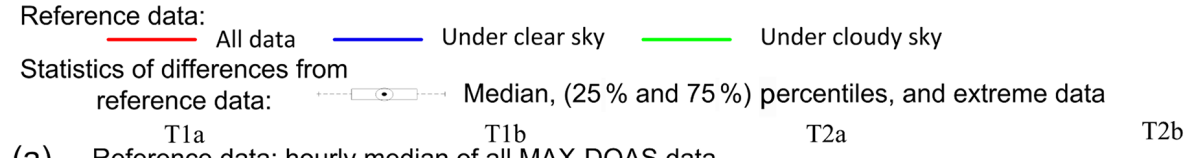

(a) Reference data: hourly median of all MAX-DOAS data
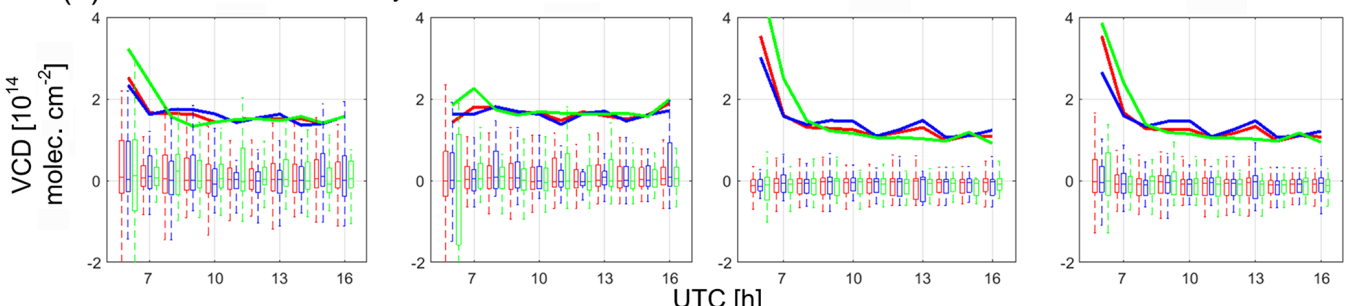

(b) Reference data: hourly median of all MAX-DOAS data
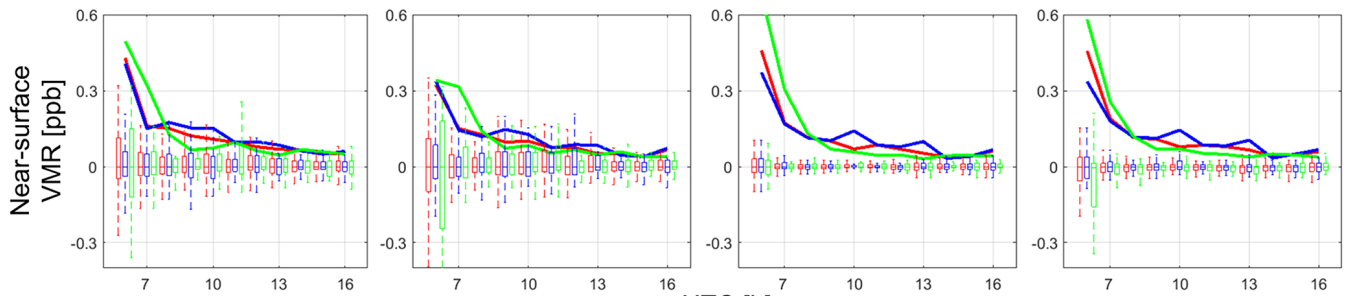

(c) Reference data: hourly median of LP-DOAS results
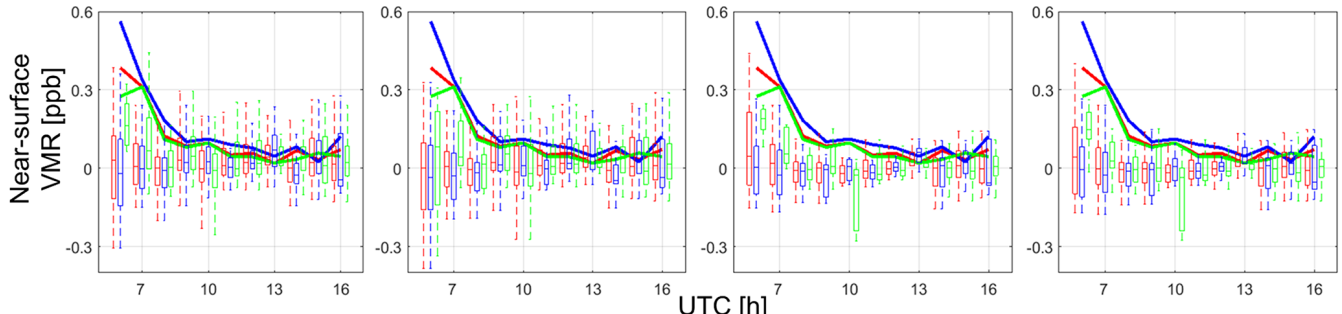

(d) Reference data: median of all MAX-DOAS data before 7h UTC
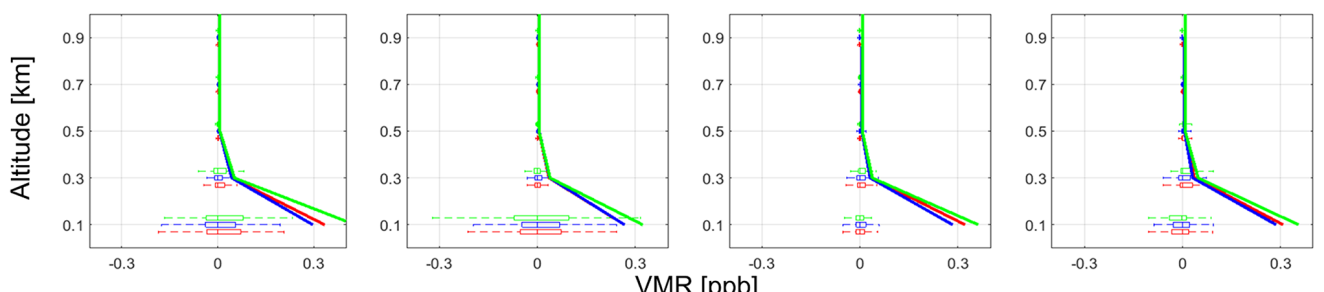

(e) Reference data: median of all MAX-DOAS data after $7 \mathrm{~h}$ UTC
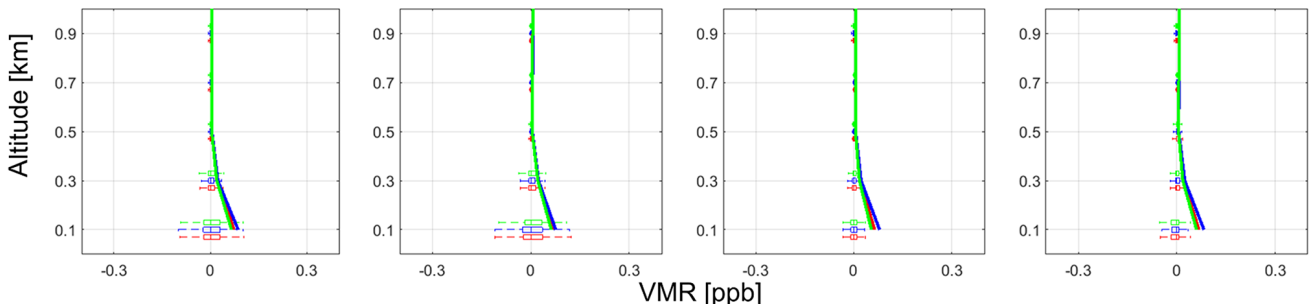

Figure 6. Boxplots of the differences of the HONO VCDs (a), near-surface VMRs (b), and profiles before (d) and after 07:00 UTC (e) derived by different institutes compared to the median values for the whole campaign. Boxplots of the differences of the HONO near-surface VMRs compared to the co-located LP-DOAS measurements are shown in (c). Note that the median values which served as the reference in the calculation of the boxplots are calculated in the individual time steps, namely each hour. Therefore, temporal variations of the quantities do not contribute to the boxplots. Colours in all subfigures indicate the sky condition. Comparisons of data sets for the four tasks are shown in the different columns of subfigures. Comparison results are calculated for different hours during the day in (a), (b), and (c). The reference values for the comparisons are also given by the solid lines in each subfigure. The reference values are the hourly median of HONO VCDs (a), near-surface VMRs (b), and profiles before (d) and after 07:00 UTC (e) derived from all MAX-DOAS data and near-surface VMRs derived from the co-located LP-DOAS measurements (c), respectively. 
the comparisons are described in Sect. 2.3.3. The median differences and half interquartile ranges are mostly in the ranges of $\pm 0.05 \mathrm{ppb}(\sim 10 \%$ to $\sim 50 \%)$ and $0.1 \mathrm{ppb}(\sim 20 \%$ to $\sim 100 \%$ ) for the four tasks. Systematically larger interquartile ranges are found in the early morning.

\subsubsection{Cloud effects on the HONO profile results}

In order to evaluate effects of clouds on the consistency of the HONO profile retrieval results, all quantities in Fig. 6 are separately shown for the measurements under "clear-sky" and "cloudy-sky" conditions. In general, similar values for the upper and lower quartiles are found for both clear- and cloudy-sky conditions, except for tasks T1a and T1b. The interquartile ranges under "cloudy-sky" conditions are $\sim 10 \%$ larger than those under "clear-sky" conditions for tasks T1a and $\mathrm{T} 1 \mathrm{~b}$, which is probably related to the larger random discrepancies of the HONO delta SCDs measured by different instruments (see Fig. 2c and Sect. 3.2).

\subsection{Comparison results for individual participants}

For the HONO near-surface VMRs and VCDs derived from the profile retrievals of the individual participants, linear regressions against the median values are performed. The derived correlation coefficients, slopes, intercepts, as well as rms of the residuals are shown in Fig. 7a and c. The median values and standard deviations of the differences of the individual data sets from the median values are also presented in Fig. $7 \mathrm{a}$ and $\mathrm{c}$, and for the vertical profiles in the three altitude intervals of 0 to $0.2 \mathrm{~km}, 0.2$ to $0.4 \mathrm{~km}$, and 0.4 to $4 \mathrm{~km}$, in Fig. 8. For the intercepts, rms, and median differences shown in Fig. 7, the corresponding "typical percentages" (relative differences compared to a typical large HONO near-surface VMR of $0.4 \mathrm{ppb}$ and VCD of $3 \times 10^{14}$ molec. $\mathrm{cm}^{-2}$ ) are also shown (see the $y$ axis on the right-hand side). Additionally, for the comparison results of the near-surface HONO VMRs versus the LP-DOAS measurements, the same parameters as shown in Fig. 7a and c are given in Fig. 7b. The same parameters as shown in Fig. 7a and $\mathrm{c}$ are derived from the comparisons of the modelled and measured HONO delta SCDs and shown in Fig. 7d. It needs to be noted that the modelled HONO delta SCDs represent the HONO delta SCDs which are simulated by a RTM, which is included in individual profile inversion algorithms. Following the discussion in Sect. 3.3, the random and systematic discrepancies of the profile retrieval results are discussed in the following.

\subsubsection{Random discrepancies}

The rms of the differences shown in Fig. 7a and c indicates systematically smaller random discrepancies for tasks T2a and T2b than for tasks T1a and T1b. The rms values of nearsurface HONO VMRs are around $0.08 \mathrm{ppb}(\sim 20 \%)$ for all the data sets in tasks T1a and T1b. The rms values of HONO VCDs are around $0.6 \times 10^{14}$ molec. $\mathrm{cm}^{-2}(\sim 20 \%)$ for most of the data sets, with a maximum value of $\sim 0.9 \times 10^{14}$ molec. ( $\sim 30 \%$ ) found for USTC (1). In tasks T2a and T2b, the rms for the near-surface HONO VMRs and VCDs is typically around $0.02 \mathrm{ppb}(\sim 5 \%)$ and $0.2 \times 10^{14}$ molec. $\mathrm{cm}^{-2}$ $(\sim 7 \%)$, respectively. The largest rms values of the nearsurface HONO VMRs and VCDs are $0.06 \mathrm{ppb}(\sim 15 \%)$ and $0.7 \times 10^{14}$ molec. $(\sim 25 \%)$, respectively, which are found for "MPIC (PriAM)" and "MPIC (MAPA)". However, the rms decreases dramatically if quality flags are applied to the "MPIC (MAPA)" data to derive the "MPIC (MAPA valid)" data. The standard deviations of the differences of the vertical profiles against the median values shown in Fig. 8 indicate that the random discrepancies at altitudes above $0.2 \mathrm{~km}$ are mostly much smaller than close to the surface. The standard deviation is mostly around $0.02 \mathrm{ppb}$ in the altitude grid of 0.2 to $0.4 \mathrm{~km}$ and almost zero at altitudes above $0.4 \mathrm{~km}$. A relatively large deviation of $\sim 0.15 \mathrm{ppb}$ for "AIOFM" appears at high altitudes in task T1a, and significantly larger deviations at high altitudes are found for the "MPIC (MAPA)" data than the other data in task T2b. However, the quality-controlled "MPIC (MAPA valid)" data show similar deviations to the other data.

\subsubsection{Systematic discrepancies}

Figure $7 \mathrm{a}$ and $\mathrm{c}$ show the median differences, intercepts, and slopes derived from the comparison of the HONO nearsurface VMRs and VCDs. Similar to the HONO delta SCDs discussed in Sect. 3.3.2, the overall systematic discrepancies of near-surface VMRs and VCDs for low and high values are indicated by the slopes and intercepts, respectively. The median differences indicate that the systematic discrepancies are mostly in the range of $20 \%$ for both tasks $\mathrm{T} 1 \mathrm{a}$ and $\mathrm{T} 1 \mathrm{~b}$ and $5 \%$ for both tasks T2a and T2b. The discrepancies of the VCDs are larger between the different data sets compared to the discrepancies of the near-surface VMRs, and the correlation coefficients of the comparisons of the VCDs are smaller than those of the comparisons of the near-surface VMRs. The near-surface VMRs are thus more consistent within the data sets than the VCDs. In addition, the discrepancies for tasks T1a and T1b are 4 times larger than for tasks T2a and $\mathrm{T} 2 \mathrm{~b}$, which indicates that the discrepancies of the profile retrievals are dominated by the errors from the input HONO delta SCDs and not by the profile inversion algorithms. Additionally, the similar levels of discrepancies between tasks $\mathrm{T} 1 \mathrm{a}$ and T1b and tasks T2a and T2b indicate that the effects of the "FRS" selection and different aerosol retrievals on the discrepancies of the HONO profile retrievals are almost negligible.

The data sets with substantial systematic discrepancies will be discussed individually in the following. The "CMA" data sets show a systematic overestimation of up to $\sim 45 \%$ compared to the median values. However, Fig. 3 e indicates a systematic underestimation of the "CMA" delta SCDs compared with the median values. Since Fig. 7d indicates a sig- 
Data set:

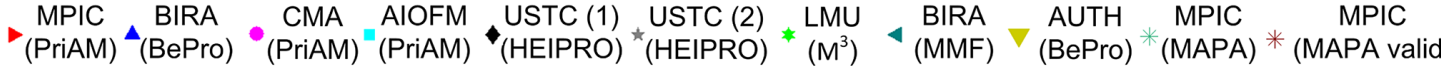

(a) For HONO surface VMR

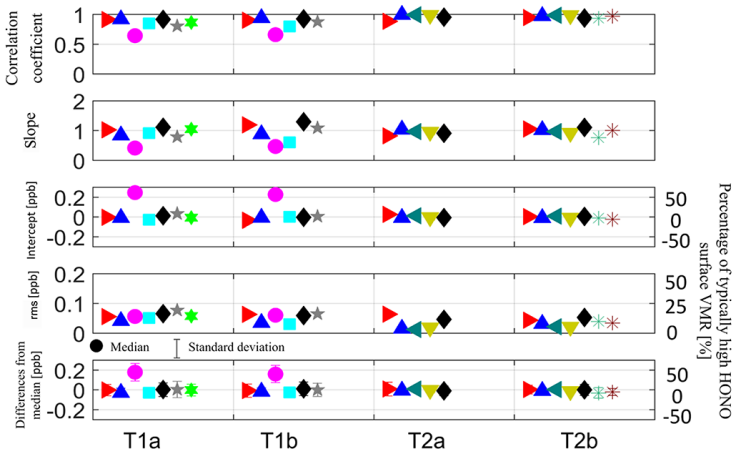

(c) For HONO VCD

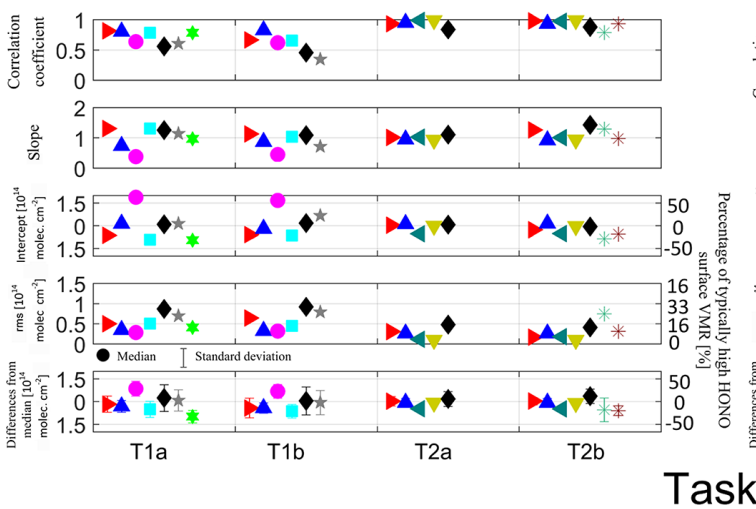

(d) (b) For surface HONO VMR comparisons with LP-DOAS
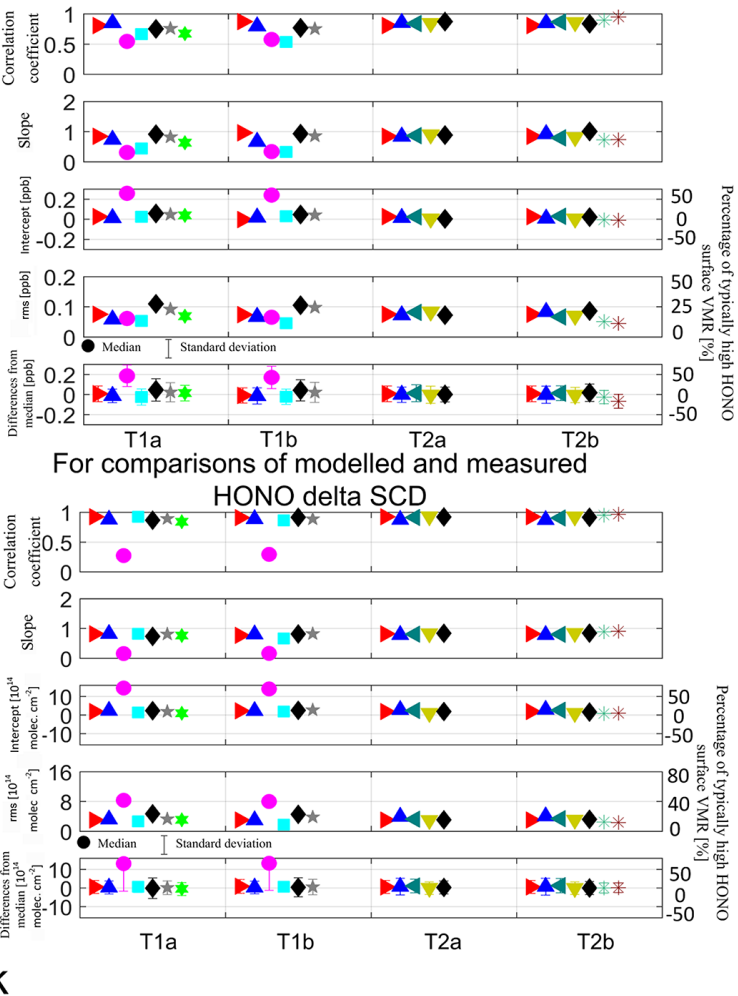

Figure 7. Correlation coefficients, slopes, intercepts, and rms of the residuals of the linear regression as well as median differences between individual participants and the reference values, which are the median values of all MAX-DOAS (a, c), and of the co-located LP-DOAS measurements (b). Comparisons of the near-surface HONO VMRs are given in (a) and (b). Comparisons of HONO VCDs are given in (c). For the individual data sets, the same comparison parameters are derived for the comparison of measured and modelled HONO delta SCDs (d).

nificant systematic overestimation of the modelled HONO delta SCDs compared to the measured ones, we conclude that the implementation of the profile inversions is the dominant factor causing a substantial overestimation of the "CMA" profile results compared to the other data. For the "LMU" data set, an overall underestimation of the VCDs, even though the near-surface VMRs are very consistent, is found because the VMRs are slightly lower than the median values at high altitudes, which can be seen in Fig. 8.

The systematic and random discrepancies between the different HONO profile results are quite comparable and typically in the range of $20 \%$ for tasks T1a and T1b and $5 \%$ for tasks T2a and T2b, with extreme discrepancies of $\sim 40 \%$ for tasks T1a and T1b and $\sim 20 \%$ for tasks T2a and T2b.

\subsubsection{Comparison with LP-DOAS}

The comparison results of the near-surface HONO VMRs of the individual participants against those measured by the co-located LP-DOAS instrument are displayed in Fig. 7b.
There the correlation coefficients, slopes, intercepts, and rms of residuals derived from the linear regressions as well as the median differences against the LP-DOAS results are shown. The median differences and intercepts are consistent with those derived from the comparisons of the individual data sets against the median values (Fig. 7a). However, the slopes of the individual participants for tasks $\mathrm{T} 1 \mathrm{a}$ and $\mathrm{T} 1 \mathrm{~b}$ are smaller than those derived from the comparisons against the median values (Fig. 7a). Therefore, in general all data sets systematically underestimate high near-surface HONO VMRs compared to the LP-DOAS results. Since the vertical layer measured by the LP-DOAS is consistent with the lowest vertical layer of the MAX-DOAS profile retrieval, the systematic differences might be mainly attributed to different air masses measured by the two techniques. It needs to be noted that MAX-DOAS typically measures the averaged HONO values in an effective light path of about $10 \mathrm{~km}$, whereas LP-DOAS measures the averaged HONO values in a light path of about $4 \mathrm{~km}$ between its telescope and re- 


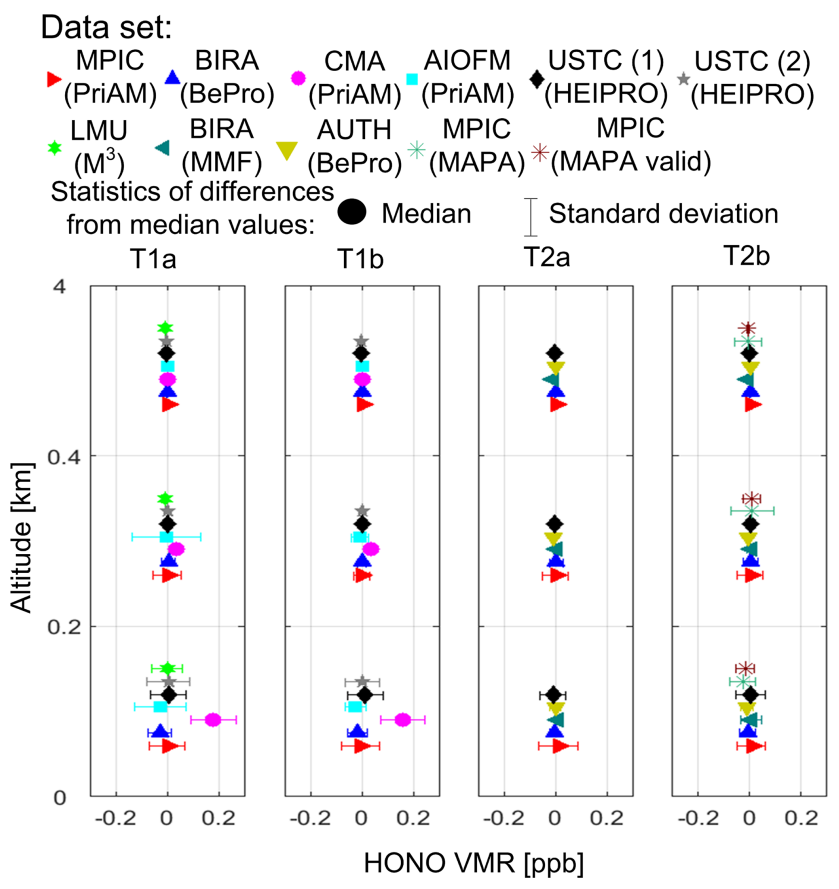

Figure 8. Median and standard deviations of the differences of the HONO VMR profiles derived from the individual participants compared to median values of all MAX-DOAS data for the whole campaign. The results in the vertical grids of 0 to $0.2 \mathrm{~km}, 0.2$ to $0.4 \mathrm{~km}$, and 0.4 to $4 \mathrm{~km}$ are shown as three vertical clusters of dots in the figures. Different subfigures represent results for different tasks.

flector. Since the typical lifetime of HONO is only of the order of $20 \mathrm{~min}$ under daytime conditions, strong HONO concentration horizontal inhomogeneities can be expected. However, the comparisons of $\mathrm{NO}_{2}$ near-surface concentrations between MAX-DOAS measurements and LP-DOAS, as given in Tirpitz et al. (2020), do not indicate a systematic underestimation of MAX-DOAS. The different feature for $\mathrm{NO}_{2}$ and $\mathrm{HONO}$ might be attributed to the much shorter lifetime of $\mathrm{HONO}$ than $\mathrm{NO}_{2}$.

For the random differences of the individual data sets against the LP-DOAS measurements, in general similar rms values are observed to those derived from the comparison against the median values (Fig. 7a) for tasks T1a and T1b. However, for tasks T2a and T2b, the rms values for "BIRA", "BIRA MMF", and "AUTH" are much larger for the comparison with LP-DOAS than those for the comparison with the median values. Therefore, we conclude that the random discrepancies might be dominated by variations of HONO concentrations in the air mass measured by the LP-DOAS. Frequent variations of HONO concentrations can be expected due to the short lifetime of HONO. The variations of HONO concentrations in the air mass measured by the MAX-DOAS instrument can be smoothed due to the averaging effect in a typical effective light path of $\sim 10 \mathrm{~km}$ length.

\section{Sensitivity studies of profile inversion}

\subsection{Sensitivity study on the effects of a priori profiles and the a priori covariance based on synthetic HONO delta SCDs}

In this section we evaluate the influence of the a priori profile on the retrieval results based on synthetic HONO delta SCDs simulated by the RTM SCIATRAN. For these simulations, three different HONO profiles are used. These profiles as well as the other input parameters used for the RTM simulations are provided in Sect. 2.3.4. Among the three participants of this sensitivity study, "INTA" and "AUTH" used the "BePro" profile inversion algorithm, whereas "MPIC" used the "PriAM" profile inversion algorithm. While "BePro" uses a linear optimal estimation method, in "PriAM" a non-linear optimal estimation approach in logarithmic space is applied. We also evaluate the effect of different definitions of a priori covariance $\left(S_{\mathrm{a}}\right)$. In the baseline setting, $S_{\mathrm{a}}$ is set to $100 \%$ of the a priori values for the diagonal terms. In the following this baseline configuration of $S_{\mathrm{a}}$ is referred to as "a priori determined $S_{\mathrm{a}}$ ". For the "BePro" algorithm, $S_{\mathrm{a}}$ is alternatively also set to a constant value at all altitudes, which is $100 \%$ of the a priori value in the lowest altitude grid. This setting of $S_{\mathrm{a}}$ is referred to as the "constant $S_{\mathrm{a}}$ ". The alternative choice of $S_{\mathrm{a}}$ can theoretically decrease the constraints of the a priori profile on the retrieved profiles. Here it should be noted that for "PriAM" the definition of $S_{\mathrm{a}}$ according to the baseline settings is changed to unity at all altitudes due to its conversion to the logarithmic space. We do not apply an alternative $S_{\mathrm{a}}$ for "PriAM".

HONO profiles are retrieved from synthetic HONO delta SCDs using three different a priori profiles (shown in Fig. 1b) and two different $S_{\mathrm{a}}$. The retrieved profiles are shown in Fig. 9 separately for the three different algorithms. It is found that for all scenarios similar results are retrieved by "INTA" and "AUTH", which apply the same "BePro" algorithm. For the tests with the a priori determined $S_{\mathrm{a}}$, both "INTA" and "AUTH" considerably overestimate the HONO VMRs near the surface and underestimate those at high altitudes for profiles 2 and 3 if a priori profile 3 is used. However, for the tests with constant $S_{\mathrm{a}}$, very consistent profile results are derived by "INTA" and "AUTH" for all three a priori profiles. This indicates that the HONO profile retrievals using "BePro" respond to the true HONO profiles much better if a "constant $S_{\mathrm{a}}$ " is used. For the "MPIC" results with the "PriAM" algorithm, very consistent profiles are also obtained for the three different a priori profiles. For profile 1 the "MPIC" retrieval agrees much better with the true profile than "INTA" and "AUTH" results. These results indicate that the "PriAM" algorithm can better respond to different HONO profile shapes through the implementation of the non-linear iterative procedure in logarithmic space. In addition, it needs to be clarified that negative values are allowed to be derived using "BePro", although they are unrealistic in the real atmosphere. In con- 


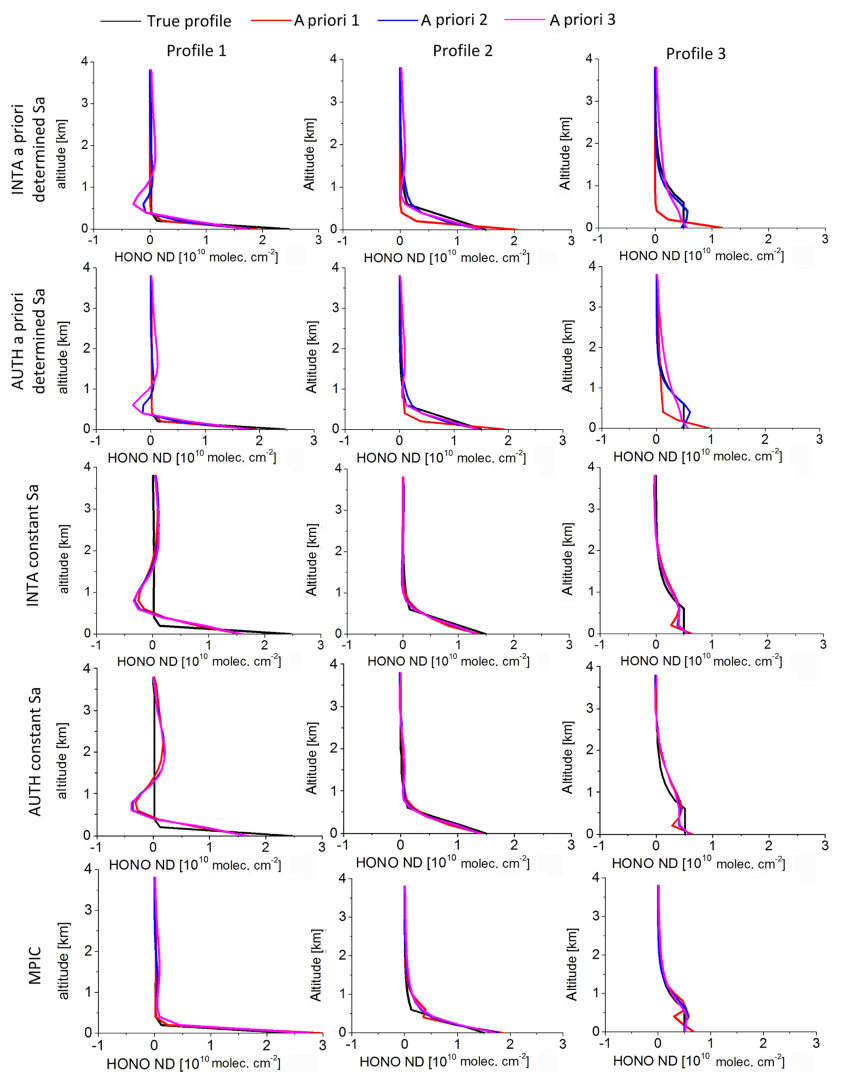

Figure 9. HONO profiles retrieved from simulated HONO delta SCDs by the different participants using different inversion algorithms with "constant Sa" and "a priori determined $\mathrm{Sa}$ " (see text). The black curves in the different columns of the figure indicate the different input profiles, and the other colours indicate the profiles retrieved using different a priori profiles (see Fig. 1b).

trast, negative values are avoided in the "PriAM" algorithm due to the logarithmic transformation.

The effects of random noise on the profile retrievals were tested based on the "noisy synthetic HONO delta SCDs", which are described in Sect. 2.3.4. Median values and standard deviations of differences of the retrieved HONO profiles compared to those retrieved from the synthetic HONO delta SCDs without noise are shown in Fig. 10, and for the same results, the ratios of the median values and standard deviations shown in Fig. 10 compared to the true HONO profiles are plotted in Fig. 11. The results for the retrievals using the "a priori determined $S_{\mathrm{a}}$ " and "constant $S_{\mathrm{a}}$ " are shown separately in Figs. 10 and 11. For "INTA" and "AUTH", much larger standard deviations for retrievals using the "constant $S_{\mathrm{a}}$ " than those using the "a priori determined $S_{\mathrm{a}}$ " at high altitudes are found due to the smaller a priori constraints if the "constant $S_{\mathrm{a}}$ " is used. For "MPIC", standard deviations at altitudes below $1 \mathrm{~km}$ are similar to those for "INTA" and "AUTH" with the "constant $S_{\mathrm{a}}$ ". However, much smaller standard deviations are found at altitudes above $1 \mathrm{~km}$.

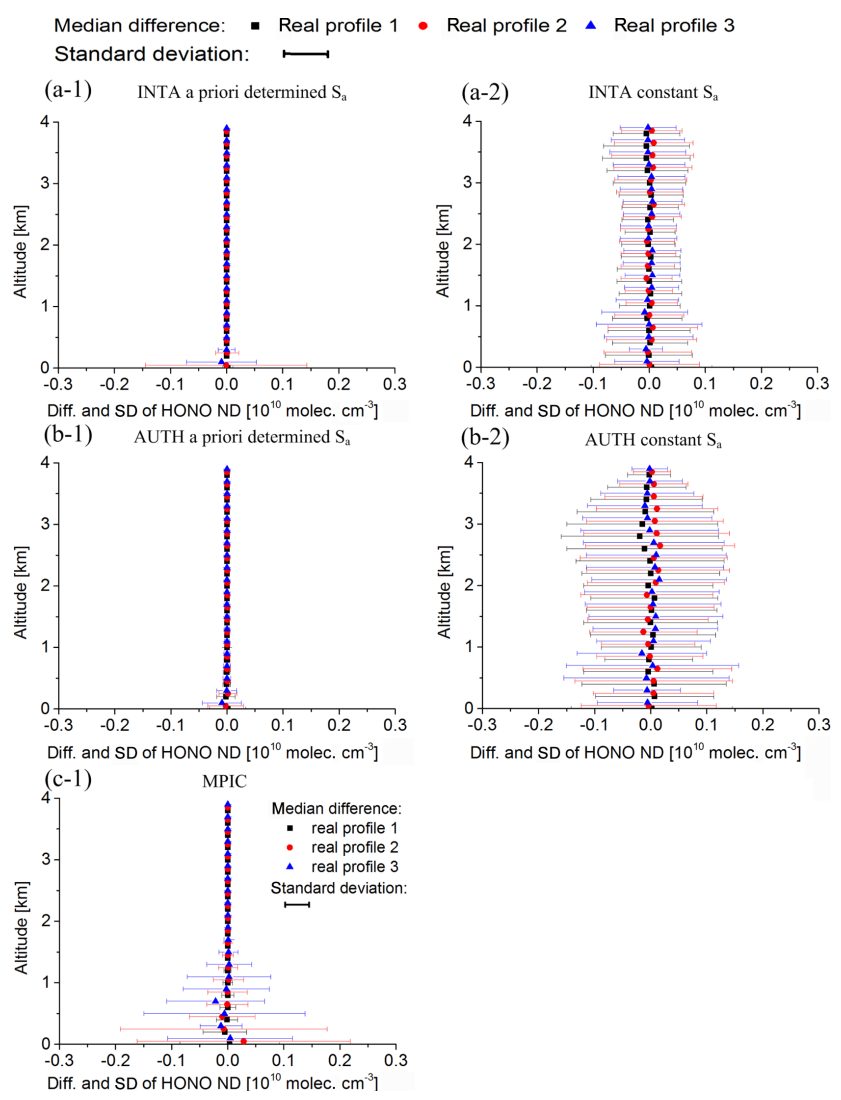

Figure 10. Median and standard deviations of the differences of the HONO VMR profiles retrieved from the simulated HONO delta SCDs with added artificial noise compared to those without noise by the different participants using a different inversion algorithm with "constant $\mathrm{Sa}$ " and "a priori determined $\mathrm{Sa}$ " (see text). The root mean square of the noise is $3 \times 10^{14}$ molec. $\mathrm{cm}^{-2}$. The different colours indicate the results for the three different assumed HONO profiles.

We conclude that for the "BePro" algorithm, the "constant $S_{\mathrm{a}}$ " can increase the response of the profile retrievals to different HONO profile shapes but can reduce the stability. The "PriAM" algorithm can balance the response and stability well. Therefore we recommend retrieving HONO profiles in logarithmic space.

\subsection{Sensitivity study on the effects of the grid intervals in the profile retrievals}

In the baseline settings of the profile retrievals the grid intervals were set to $200 \mathrm{~m}$. Since a significant vertical gradient might appear in the lowest $200 \mathrm{~m}$, we tested the effects of using different grid intervals, e.g. 50 and $100 \mathrm{~m}$, on the retrieved profiles using the "PriAM" algorithm based on the "MPIC"-measured HONO delta SCDs during the whole campaign. For different grid intervals, the averaged diurnal variations of the retrieved HONO VMRs below $200 \mathrm{~m}$ are shown in Fig. 12a. Differences of the retrieved HONO VMRs 

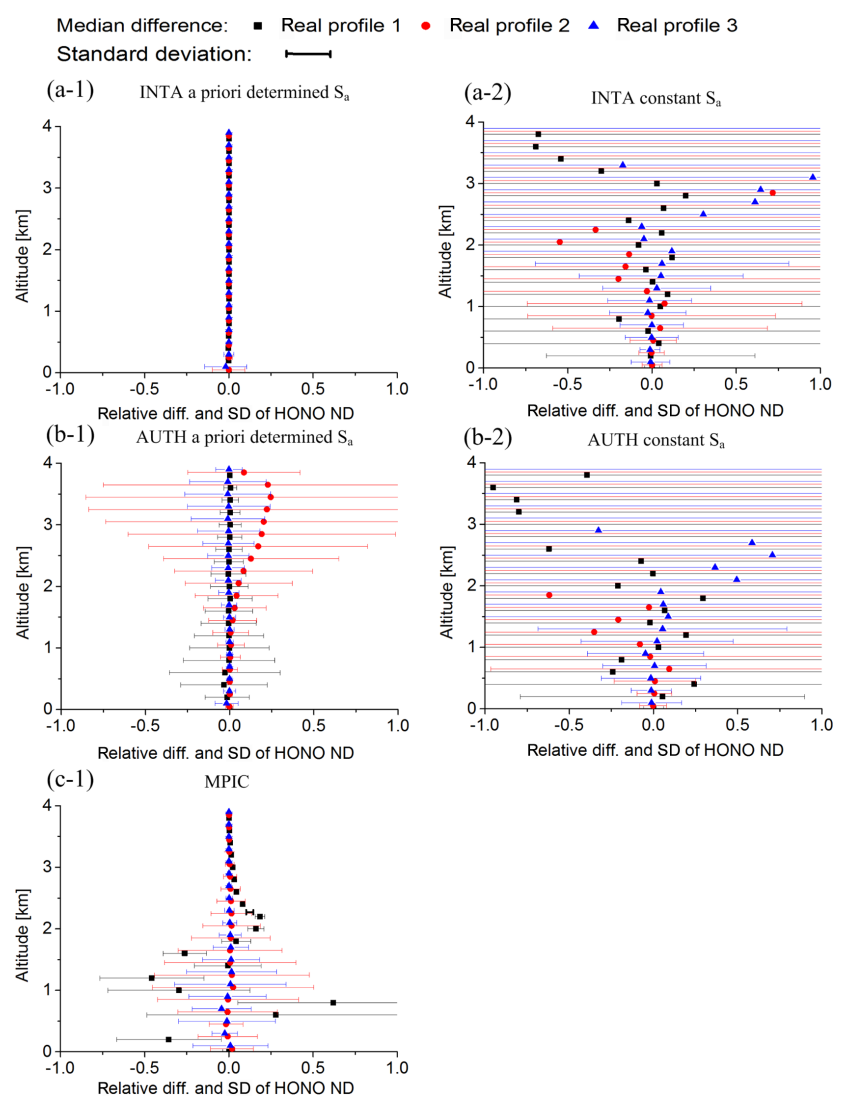

Figure 11. Median and standard deviations of the relative differences of the HONO VMR profiles retrieved from the simulated HONO delta SCDs with added artificial noise compared to those without noise by the different participants using a different inversion algorithm with "constant $\mathrm{Sa}$ " and "a priori determined $\mathrm{Sa}$ " (see text).

using grid intervals of 100 and $50 \mathrm{~m}$ compared to the baseline setting are shown in Fig. 12b. Figure 12 indicates that the retrieved HONO VMRs below $100 \mathrm{~m}$ for both retrievals with grid intervals of 50 and $100 \mathrm{~m}$ are similar to those grid intervals of $200 \mathrm{~m}$ (baseline settings). The retrieved HONO VMRs significantly decrease in the grids above $100 \mathrm{~m}$. Based on this sensitivity test, it is concluded that a finer resolution than $200 \mathrm{~m}$ can improve the profile results in the altitude range below $200 \mathrm{~m}$.

\subsection{Measurement uncertainties of HONO dSCDs and their effects on profile retrievals}

In order to calculate the diagonal elements of the covariance matrix of measurement uncertainties for profile retrievals using the optimal estimation method, measurement uncertainties of HONO dSCDs need to be estimated. Measurement uncertainties can be mainly attributed to instrumental noise and atmospheric variability. DOAS fit errors provide a good representation of the instrumental noise. In the baseline settings of profile retrievals, we assume that measurement un- certainties and DOAS fit errors of HONO dSCDs are equivalent. However, this assumption is not realistic if the effect of atmospheric variability is significantly larger than DOAS fit errors. As shown in Fig. 3f, the lowest DOAS fit errors of $\sim 0.1 \times 10^{15}$ molec. $\mathrm{cm}^{-2}$ are found for the BIRA instrument, and they are 3 times lower than the typical DOAS fit error of $\sim 0.3 \times 10^{15}$ molec. $\mathrm{cm}^{-2}$ of the other instruments as shown in Fig. 2c. Two data sets of HONO profile results are derived from the same HONO dSCD data sets with different settings of the diagonal elements of the measurement uncertainty covariance matrix. The baseline profile retrieval settings (i.e. $100 \%$ of the DOAS fit errors of the HONO dSCDs) are applied for the retrievals of the "BIRA (v1)" data set, while the "BIRA (v2)" data set corresponds to the BePRO profile retrievals where $300 \%$ of the DOAS fit errors of the HONO dSCDs is used. Figure 5 indicates that the "BIRA (v1)" results deviate more from the median values than those of "BIRA (v2)". This feature is due to the fact that the measurement uncertainties of the "BIRA" instrument are substantially larger than its DOAS fit errors, due to the effect of atmospheric variability. In order to realistically estimate measurement uncertainties, the standard deviations of the "BIRA" HONO dSCDs retrieved using the daily noon FRS in the time period of 11:00 to 16:00 UTC on individual days are shown in Fig. 13a. Since HONO dSCDs, especially in the zenith view, are close to zero as shown in Fig. 2b, the standard deviations can represent random measurement uncertainties. Since the DOAS fit errors of the "MPIC" data set are in the moderate range of all the participating instruments, the standard deviations of the "MPIC" data set are calculated and shown in Fig. 13b for comparisons with the "BIRA" data set. In addition, the averaged DOAS fit errors of HONO dSCDs of both data sets are shown in Fig. 13c, d. Figure 13 indicates that although the DOAS fit errors of the "BIRA" data set are about one-third of the "MPIC" data set, the standard deviations of both the "MPIC" and "BIRA" data sets are comparable and around 0.2 to $0.3 \times 10^{15}$ molec. $\mathrm{cm}^{-2}$. This feature suggests that measurement uncertainties are similar for both the "MPIC" and "BIRA" data sets due to the dominant effect of atmospheric variability on the measurement uncertainties of the "BIRA" data set. In contrast to the "BIRA" case, both atmospheric variability and instrumental noise are comparable in the "MPIC" data set. Since the measurement uncertainties are about 3 times higher than the DOAS fit errors for the "BIRA" instrument, the setting for the "BIRA (v2)" profile results is more realistic that for the "BIRA (v1)" profile results. However, for the "MPIC" instrument and most of the other instruments, since the measurement uncertainties are comparable to the DOAS fit errors, baseline settings are reasonable. We can conclude that not only DOAS fit errors, but also atmospheric variability should be considered for the estimation of measurement uncertainties for profile retrievals. The effect of atmospheric variability on measurement uncertainties of HONO dSCDs is roughly around 0.2 to $0.3 \times 10^{15}$ molec. $\mathrm{cm}^{-2}$, which might be significantly larger 

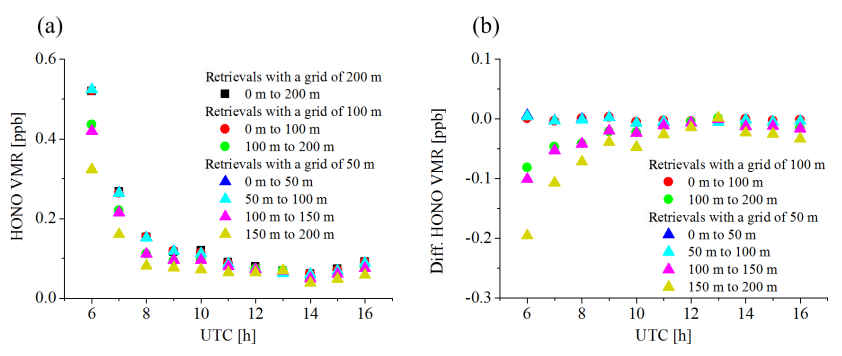

Figure 12. (a) Averaged diurnal variations of the HONO VMRs in the altitude range of up to $200 \mathrm{~m}$ retrieved using the "PriAM" algorithm using vertical grid intervals of 50, 100, and $200 \mathrm{~m}$, respectively. Note that the results in the altitude grids below $200 \mathrm{~m}$ are given, respectively. The results are derived from the HONO delta SCD measured by the MPIC instrument. (b) Averaged diurnal variations of the differences of the HONO VMRs retrieved for vertical grid intervals of $50 \mathrm{~m}$ and $100 \mathrm{~m}$ compared to those retrieved for the vertical grid interval of $200 \mathrm{~m}$.

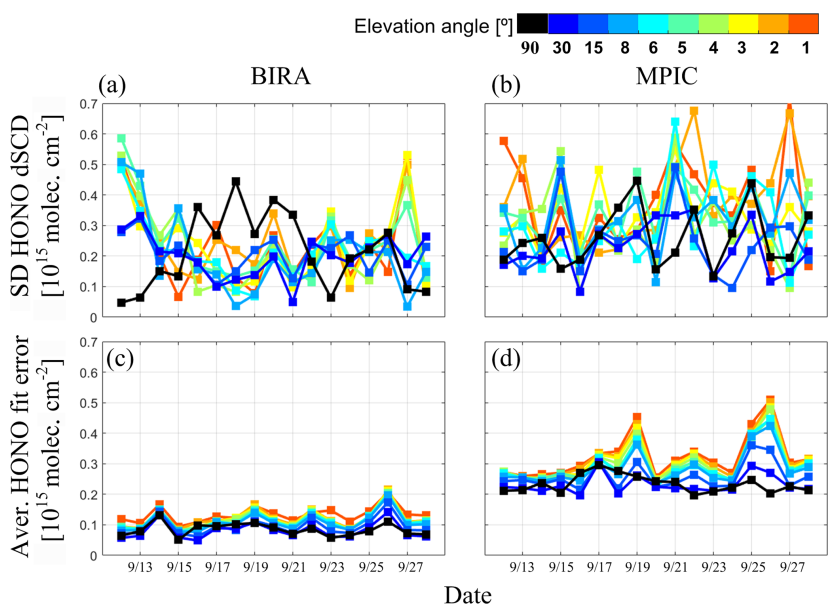

Figure 13. Standard deviations (a, b) and averaged DOAS fit errors (c, d) of HONO dSCDs retrieved using the daily noon FRS in the time period of 11:00 to 16:00 UTC for individual days for the BIRA (a, c) and MPIC (b, d) instruments, respectively. The colour map indicates elevation angles.

than DOAS fit errors of a state-of-the-art MAX-DOAS instrument with high signal-to-noise ratios.

\section{Conclusions}

In this study, HONO delta SCDs and vertical profiles are retrieved from different MAX-DOAS observations during the CINDI-2 campaign. VCDs and near-surface VMRs are derived using different profile inversion algorithms, which are applied to HONO delta SCDs analysed by the different participants. Peak HONO values with delta SCDs at $1^{\circ}$ elevation angle of $\sim 3 \times 10^{15}$ molec., VCDs of $3 \times 10^{14}$ molec. $\mathrm{cm}^{-2}$, and near-surface VMRs of $0.4 \mathrm{ppb}$ on average are retrieved in the early morning. These are followed by a steep decrease to $\sim 1.2 \times 10^{15}$ molec. $\mathrm{cm}^{-2}, \sim 1.5 \times 10^{14}$ molec. $\mathrm{cm}^{-2}$, and $\sim 0.1 \mathrm{ppb}$, respectively, during the period from 06:00 to 08:00 UTC. Afterwards, the HONO values stay low and further decrease slightly during the rest of the day. The profile results indicate that most of the HONO accumulates at altitudes below $0.2 \mathrm{~km}$, and $\mathrm{HONO}$ concentrations are close to zero at altitudes above $0.4 \mathrm{~km}$ during the day.

We evaluated random and systematic differences between different retrieval results of HONO delta SCDs derived from different MAX-DOAS instruments using different inversion algorithms. It needs to be clarified that the data samplings are limited in the statistic study, and thus the uncertainties of the HONO delta SCDs (and other HONO results including VCDs, near-surface VMRs, and profiles) can only be roughly estimated for typical cases. For MAX-DOAS instruments with moderate performance during this campaign, the systematic discrepancies of the delta SCDs of the different MAX-DOAS instruments are generally in the range of $\pm 0.3 \times 10^{15}$ molec. $\mathrm{cm}^{-2}$, which is half of the typical random uncertainty of $\sim 0.6 \times 10^{15}$ molec. $\mathrm{cm}^{-2}$. For a typical high value of HONO delta SCD of $2 \times 10^{15}$ molec. $\mathrm{cm}^{-2}$, the typical relative systematic and random uncertainties are about $15 \%$ and $30 \%$, respectively. Similar magnitudes of random and systematic uncertainties are observed for different elevation angles. However, since the HONO delta SCDs decrease with increasing elevation angle, the relative random and systematic uncertainties reach up to $200 \%-400 \%$ and $100 \%-200 \%$, respectively, for the $30^{\circ}$ elevation angle. The HONO delta SCDs retrieved by some participants show substantially larger random and systematic discrepancies compared to most participants, which is mainly caused by limitations of the instrumental signal-to-noise ratios or an inappropriate implementation of DOAS fits. Another important finding is that for most instruments the random discrepancies of HONO delta SCD results between the different instruments are significantly larger than individual DOAS fit errors due to the effects of atmospheric variability and discrepancies of instrumental FOV and acquisition time. In addition, for most of the instruments, the effects of using either a "sequential FRS" or "daily noon FRS" on the errors of the HONO delta SCDs are practically negligible, with systematic and random differences between both retrieval results typically within $\pm 0.1 \times 10^{15}$ molec. $\mathrm{cm}^{-2}(\sim \pm 5 \%)$.

Random and systematic differences between the retrieved HONO VCDs, near-surface VMRs, and profiles from the different MAX-DOAS instruments and inversion algorithms are further evaluated via statistical inter-comparison. Both systematic and random differences of HONO VCDs and near-surface VMRs are typically $\sim 20 \%$. For some instruments, the maximum random and systematic discrepancies are $\sim 40 \%$. In order to better understand the reasons for the differences, all participants also retrieved $\mathrm{HONO}$ profiles from a set of common HONO delta SCDs using their specific inversion algorithms. The results of this task indicate that the differences of the profile inversion algorithms gener- 
ally contribute to both systematic and random discrepancies of the HONO VCDs at about $\sim \pm 0.2 \times 10^{14}$ molec. $\mathrm{cm}^{-2}$ and of the near-surface VMRs at about $\sim \pm 0.02 \mathrm{ppb}$ (typically $\sim 5 \%$ for both VCDs and near-surface VMRs). These results indicate that the errors of the HONO delta SCDs dominate the differences of $\mathrm{HONO}$ profile results. Further error sources, especially for the most extreme discrepancies, are probably inappropriate implementations of the profile inversion algorithms and/or configurations of the profile retrievals. Both systematic and random discrepancies are considerably higher in the lowest altitude range of 0 to $0.2 \mathrm{~km}$, mostly $\sim 0.02 \mathrm{ppb}$ in the altitude range from 0.2 to $0.4 \mathrm{~km}$, and almost zero above. In addition, the effect of using a "daily noon FRS" or a "sequential FRS" in the DOAS fit on the profile results is almost negligible. Also, the effect of different aerosol retrievals on HONO profile results is typically negligible.

The near-surface HONO VMRs retrieved from different MAX-DOAS measurements are also compared to the colocated LP-DOAS measurements. In general, the systematic discrepancies of the individual MAX-DOAS measurements compared to the LP-DOAS results are similar to those derived from the comparison with the median values of all MAX-DOAS results. Interestingly, the median values of all MAX-DOAS measurements are systematically lower or higher than the LP-DOAS results by up to $0.15 \mathrm{ppb}(\sim$ $50 \%)$ and $0.07 \mathrm{ppb}(\sim 20 \%-200 \%)$ in the early morning and around noon, respectively.

The effects of a priori profiles and covariance for the "BePro" and "PriAM" profile inversion algorithms, which are both based on the optimal estimation method but in linear and logarithmic space, respectively, were evaluated using simulated delta SCDs for three different altitude profiles. The results of this sensitivity study indicate that a "constant $\mathrm{Sa}$ " for the "BePro" algorithm in linear space can increase the response of the profile retrievals to different HONO profile shapes but tends to reduce the stability. The "PriAM" algorithm in logarithmic space can balance the response and stability well. Therefore we recommend retrieving HONO profiles in logarithmic space. Additional sensitivity tests indicate that a finer resolution than $200 \mathrm{~m}$ improves the retrieved profiles in the altitude range below $200 \mathrm{~m}$. In addition it is found that measurement uncertainties of HONO dSCDs, which are needed to calculate the measurement uncertainty covariance matrix for profile retrievals using the optimal estimation method, can be significantly larger than DOAS fit errors due to the effect of atmospheric variability, especially for an instrument with a low noise level. This may lead to unrealistic estimations of measurement uncertainties causing considerable discrepancies in profile results. Therefore, not only DOAS fit errors, but also the effect of atmospheric variability, need to be considered for the estimation of measurement uncertainties. The typical contribution of atmospheric variability to measurement uncertainties of HONO dSCDs is about 2 to $3 \times 10^{14}$ molec. $\mathrm{cm}^{-2}$, but it might depend on particular sky conditions and instrumental properties.
We summarize that, even though the errors of the measured HONO delta SCDs usually dominate the errors of the retrieved HONO profiles, the inappropriate implementation of the profile inversion algorithms can also cause substantial discrepancies. Profile inversion algorithms with proper configuration can retrieve different HONO profile shapes well, especially in logarithmic space. This confirms that one important feature of the retrieved HONO profiles, the high concentrations near the surface, represents the ambient HONO vertical distribution well during the CINDI-2 campaign.

Data availability. Data are publicly available upon request.

Author contributions. YW prepared the paper with contributions from all the co-authors. All the co-authors contributed to modifications and discussions in preparing the manuscript. Individually SD, TW, and YW operated the instrument and evaluated data of the MPIC group. SB performed the profile inversion with the MAPA algorithm. AH performed the radiative transfer simulations for the synthetic dSCDs. SS prepared and operated the LP-DOAS instrument and evaluated the corresponding data. CZ, ZW, and KLC operated the USTC-DLR instruments. CZ, ZW, HL, CX, and CL evaluated the USTC-DLR measurement data. CL managed all the USTC-DLR activities. KLC operated the LMU instrument and evaluated the measurement data. TD and $\mathrm{AB}$ operated the instrument and evaluated data of the Aristotle University of Thessaloniki. PJ and RQ each operated a MAX-DOAS instrument and processed its data on behalf of the NIWA group. MVR and FH contributed to the design and planning of the CINDI-2 campaign, operated a MAXDOAS instrument, and evaluated SCD and profile data on behalf of the BIRA group. MMF performed the profile retrievals using the MMF algorithm. NB, DG-N, and AS-L operated the instrument and evaluated data from the Department of Atmospheric Chemistry and Climate, IQFR-CSIC. JLJ and JZM operated the instrument and evaluated data of the CMA. AB and OP operated the AMOIAP instrument and evaluated its data. MY provided financial support and resources and scientific discussion for the INTA group. LG-M performed vertical profile simulations of INTA. J-LT contributed to the graphical representation of the inter-comparison results and the scientific discussion. TKK, HF, and RV operated the instruments and evaluated data for CU Boulder. KK was the referee for the CINDI-2 inter-comparison campaign and as such was involved in the day-today campaign management and data quality checks of all CINDI-2 MAX-DOAS measurements. JX, XT, and PX operated the instrument and evaluated data of the Anhui Institute of Optics and Fine Mechanics (AIOFM).

Competing interests. The authors declare that they have no conflict of interest.

Acknowledgements. We are grateful to the KNMI staff at Cabauw for their excellent technical and infrastructural support during the campaign. Funding for this study was provided by ESA through the CINDI-2 (ESA contract no. 4000118533/16/I-Sbo) and 
FRM4DOAS (ESA contract no. 4000118181/16/I-EF) projects. We would like to thank Marc Allaart for the provision of pressure and temperature sonde measurements in De Bilt via the NDACC database. The CMA group is grateful for the support by the NSFC under project no. 41805027. Work of the AMOIAP group was supported by the Russian Foundation for Basic Research (grant no. 18-35-00682) and the Russian Academy of Sciences (grant nos. 0150-2018-0052, 0129-2019-0002). SCIATRAN simulations were performed on HPC cluster Aether at the University of Bremen, financed by the DFG in the scope of the Excellence Initiative. Rainer Volkamer is grateful for funding from NASA's Atmospheric Composition Program (NASA-16-NUP2016-0001) and the US National Science Foundation (award AGS-1620530). Henning Finkenzeller is the recipient of a NASA graduate fellowship. Ka Lok Chan received funding from the European Union's Horizon 2020 research and innovation programme through the ACTRIS-2 transnational access programme (grant no. 654109). The AIOFM group is grateful for the support by the NSFC (grant no. 41530644).

Financial support. Funding for this study was provided by ESA through the CINDI-2 (ESA contract no. 4000118533/16/I-Sbo) and FRM4DOAS (ESA contract no. 4000118181/16/I-EF) projects, by the NSFC (grant no. 41805027), the Russian Foundation for Basic Research (grant no. 18-35-00682), the Russian Academy of Sciences (grant nos. 0150-2018-0052 and 0129-20190002), NASA's Atmospheric Composition Program (grant no. NASA-16-NUP2016-0001), the US National Science Foundation (AGS-1620530 award), and the European Union's Horizon 2020 research and innovation programme through the ACTRIS-2 transnational access programme (grant no. 654109). The AIOFM group is grateful for the support by the NSFC (grant no. 41530644).

The article processing charges for this open-access publication were covered by the Max Planck Society.

Review statement. This paper was edited by Keding $\mathrm{Lu}$ and reviewed by two anonymous referees.

\section{References}

Apituley, A., Hendrick, F., van Roozendael, M., Richter, A., Wagner, T., Friess, U., Kreher, K., den Hoed, M., Stein-Zweers, D., Eskes, H., Scheele, R., Piters, A., Allaart, M., Jain, S., Bloch, A., Frumau, A., Merlaud, A., Tack, F., Lampel, J., Schmitt, S., Tirpitz, J.-L., Vonk, J., Berkhout, S., van der Hoff, R., and Swart, D.: Second Cabauw Intercomparison of Nitrogen Dioxide Measuring Instruments (CINDI-2) - Campaign Overview, Atm. Meas. Tech., in preparation, 2019.

Acker, K., Möller, D., Wieprecht, W., Meixner, F. X., Bohn, B., Gilge, S., Plass-Dülmer, C., and Berresheim, H.: Strong daytime production of $\mathrm{OH}$ from $\mathrm{HNO}_{2}$ at a rural mountain site, Geophys. Res. Lett., 33, L02809, https://doi.org/10.1029/2005GL024643, 2006

Akimoto, H., Takagi, H., and Sakamaki, F.: Photoenhancement of the nitrous acid formation in the surface reaction of nitrogen dioxide and water vapor: Extra radical source in smog chamber experiments, Int. J. Chem. Kinet., 19, 539-551, https://doi.org/10.1002/kin.550190606, 1987.

Alicke, B., Geyer, A., Hofzumahaus, A., Holland, F., Konrad, S., Pätz, H.W., Schäfer, J., Stutz, J., Volz-Thomas, A., and Platt, U.: $\mathrm{OH}$ formation by HONO photolysis during the BERLIOZ experiment, J. Geophys. Res.-Atmos., 108, 8247, https://doi.org/10.1029/2001JD000579, 2003.

Aliwell, S. R., Van Roozendael, M., Johnston, P. V., Richter, A., Wagner, T., Arlander, D. W., Burrows, J. P., Fish, D. J., Jones, R. L., Tørnkvist, K. K., Lambert, J.-C., Pfeilsticker, K., and Pundt, I.: Analysis for $\mathrm{BrO}$ in zenith-sky spectra: An inter-comparison exercise for analysis improvement, J. Geophys. Res., 107, D140, https://doi.org/10.1029/2001JD000329, 2002.

Bösch, T., Rozanov, V., Richter, A., Peters, E., Rozanov, A., Wittrock, F., Merlaud, A., Lampel, J., Schmitt, S., de Haij, M., Berkhout, S., Henzing, B., Apituley, A., den Hoed, M., Vonk, J., Tiefengraber, M., Müller, M., and Burrows, J. P.: BOREAS - a new MAX-DOAS profile retrieval algorithm for aerosols and trace gases, Atmos. Meas. Tech., 11, 6833-6859, https://doi.org/10.5194/amt-11-6833-2018, 2018.

Beirle, S., Dörner, S., Donner, S., Remmers, J., Wang, Y., and Wagner, T.: The Mainz profile algorithm (MAPA), Atmos. Meas. Tech., 12, 1785-1806, https://doi.org/10.5194/amt-121785-2019, 2019.

Bobrowski, N., Hönninger, G., Galle, B., and Platt, U.: Detection of bromine monoxide in a volcanic plume, Nature, 423, 273-276, 2003.

Bogumil, K., Orphal, J., Homann, T., Voigt, S., Spietz, P., Fleischmann, O. C., Vogel, A., Hartmann, M., Kromminga, H., Bovensmann, H., Frerick, J., and Burrows, J. P.: Measurements of molecular absorption spectra with the SCIAMACHY preflight model: instrument characterization and reference data for atmospheric remote-sensing in the $230-2380 \mathrm{~nm}$ region, J. Photoch. Photobio. A, 157, 167-184, 2003.

Burrows, J. P., Dehn, A., Deters, B., Himmelmann, S., Richter, A., Voigt, S., and Orphal, J.: Atmospheric remote-sensing reference data from GOME: Part 1. Temperature-dependent absorption cross-sections of $\mathrm{NO}_{2}$ in the 231-794 nm range, J. Quant. Spectrosc. Ra. Trans., 60, 1025-1031, 1998.

Chan, K. L., Wiegner, M., Wenig, M., and Pöhler, D.: Observations of tropospheric aerosols and $\mathrm{NO}_{2}$ in Hong Kong over 5 years using ground based MAX-DOAS, Sci. Total Environ., 619-620, 1545-1556, https://doi.org/10.1016/j.scitotenv.2017.10.153, 2018.

Clémer, K., Van Roozendael, M., Fayt, C., Hendrick, F., Hermans, C., Pinardi, G., Spurr, R., Wang, P., and De Mazière, M.: Multiple wavelength retrieval of tropospheric aerosol optical properties from MAXDOAS measurements in Beijing, Atmos. Meas. Tech., 3, 863-878, https://doi.org/10.5194/amt-3-863-2010, 2010.

Danckaert, T., Fayt, C., Van Roozendael, M., De Smedt, I., Letocart, V., Merlaud, A., and Pinardi, G.: QDOAS Software User Manual Version 3.2, Belgian Institute for Space Aeronomy (BIRAIASB), 2017.

Donner, S.: Mobile MAX-DOAS measurements of the tropospheric formaldehyde column in the Rhein - Main Region, Master Thesis, Institute for Atmospheric Physics of the Johannes Gutenberg University Mainz, 2016.

Donner, S., Kuhn, J., Van Roozendael, M., Bais, A., Beirle, S., Bösch, T., Bognar, K., Bruchkouski, I., Chan, K. L., Dörner, 
S., Drosoglou, T., Fayt, C., Frieß, U., Hendrick, F., Hermans, C., Jin, J., Li, A., Ma, J., Peters, E., Pinardi, G., Richter, A., Schreier, S. F., Seyler, A., Strong, K., Tirpitz, J.-L., Wang, Y., Xie, P., Xu, J., Zhao, X., and Wagner, T.: Evaluating different methods for elevation calibration of MAX-DOAS (Multi AXis Differential Optical Absorption Spectroscopy) instruments during the CINDI-2 campaign, Atmos. Meas. Tech., 13, 685-712, https://doi.org/10.5194/amt-13-685-2020, 2020.

Emde, C., Buras-Schnell, R., Kylling, A., Mayer, B., Gasteiger, J., Hamann, U., Kylling, J., Richter, B., Pause, C., Dowling, T., and Bugliaro, L.: The libRadtran software package for radiative transfer calculations (version 2.0.1), Geosci. Model Dev., 9, 1647-1672, https://doi.org/10.5194/gmd-9-1647-2016, 2016.

Elshorbany, Y. F., Kleffmann, J., Kurtenbach, R., Lissi, E., Rubio, M., Villena, G., Gramsch, E., Rickard, A. R., Pilling, M. J., and Wiesen, P.: Seasonal dependence of the oxidation capacity of the city of Santiago de Chile, Atmos. Environ., 44, 5383-5394, 2010.

Fayt, C. and van Roozendael, M.: WinDOAS 2.1 Software User Manual, IASB/BIRA, available at: http://bro.aeronomie. be/WinDOAS-SUM-210b.pdf (last access: 20 September 2020), 2001.

Fleischmann, O. C., Hartmann, M., Burrows, J. P., and Orphal, J.: New ultraviolet absorption cross-sections of $\mathrm{BrO}$ at atmospheric temperatures measured by time-windowing Fourier transform spectroscopy, J. Photochem. Photobiol. A, 168, 117-132, 2004.

Friedrich, M. M., Rivera, C., Stremme, W., Ojeda, Z., Arellano, J., Bezanilla, A., García-Reynoso, J. A., and Grutter, M.: $\mathrm{NO}_{2}$ vertical profiles and column densities from MAX-DOAS measurements in Mexico City, Atmos. Meas. Tech., 12, 2545-2565, https://doi.org/10.5194/amt-12-2545-2019, 2019.

Frieß, U., Monks, P. S., Remedios, J. J., Rozanov, A., Sinreich, R., Wagner, T., and Platt, U.: MAX-DOAS $\mathrm{O}_{4}$ measurements: A new technique to derive information on atmospheric aerosols: 2. Modeling studies, J. Geophys. Res., 111, D14203, https://doi.org/10.1029/2005JD006618, 2006.

Frieß, U., Sihler, H., and Sander, R.: The vertical distribution of BrO and aerosols in the Arctic: Measurements by active and passive differential optical absorption spectroscopy, J. Geophys. Res., 116, D00R04, https://doi.org/10.1029/2011JD015938, 2011.

Frieß, U., Klein Baltink, H., Beirle, S., Clémer, K., Hendrick, F., Henzing, B., Irie, H., de Leeuw, G., Li, A., Moerman, M. M., van Roozendael, M., Shaiganfar, R., Wagner, T., Wang, Y., Xie, P., Yilmaz, S., and Zieger, P.: Intercomparison of aerosol extinction profiles retrieved from MAX-DOAS measurements, Atmos. Meas. Tech., 9, 3205-3222, https://doi.org/10.5194/amt-9-32052016, 2016.

Frieß, U., Beirle, S., Alvarado Bonilla, L., Bösch, T., Friedrich, M. M., Hendrick, F., Piters, A., Richter, A., van Roozendael, M., Rozanov, V. V., Spinei, E., Tirpitz, J.-L., Vlemmix, T., Wagner, T., and Wang, Y.: Intercomparison of MAX-DOAS vertical profile retrieval algorithms: studies using synthetic data, Atmos. Meas. Tech., 12, 2155-2181, https://doi.org/10.5194/amt12-2155-2019, 2019.

Hartl, A. and Wenig, M. O.: Regularisation model study for the least-squares retrieval of aerosol extinction time series from UV/VIS MAX-DOAS observations for a ground layer profile parameterisation, Atmos. Meas. Tech., 6, 1959-1980, https://doi.org/10.5194/amt-6-1959-2013, 2013.
Hendrick, F., Müller, J.-F., Clémer, K., Wang, P., De Mazière, M., Fayt, C., Gielen, C., Hermans, C., Ma, J. Z., Pinardi, G., Stavrakou, T., Vlemmix, T., and Van Roozendael, M.: Four years of ground-based MAX-DOAS observations of HONO and $\mathrm{NO}_{2}$ in the Beijing area, Atmos. Chem. Phys., 14, 765-781, https://doi.org/10.5194/acp-14-765-2014, 2014.

Hönninger, G. and Platt, U.: Observations of BrO and its vertical distribution during surface ozone depletion at Alert, Atmos. Environ., 36, 2481-2489, 2002.

Hönninger, G., von Friedeburg, C., and Platt, U.: Multi axis differential optical absorption spectroscopy (MAX-DOAS), Atmos. Chem. Phys., 4, 231-254, https://doi.org/10.5194/acp-4231-2004, 2004.

Irie, H., Kanaya, Y., Akimoto, H., Iwabuchi, H., Shimizu, A., and Aoki, K.: First retrieval of tropospheric aerosol profiles using MAX-DOAS and comparison with lidar and sky radiometer measurements, Atmos. Chem. Phys., 8, 341-350, https://doi.org/10.5194/acp-8-341-2008, 2008.

Irie, H., Takashima, H., Kanaya, Y., Boersma, K. F., Gast, L., Wittrock, F., Brunner, D., Zhou, Y., and Van Roozendael, M.: Eight-component retrievals from ground-based MAXDOAS observations, Atmos. Meas. Tech., 4, 1027-1044, https://doi.org/10.5194/amt-4-1027-2011, 2011.

Jin, J., Ma, J., Lin, W., Zhao, H., Shaiganfar, R., Beirle, S. and Wagner, T.: MAX-DOAS measurements and satellite validation of tropospheric $\mathrm{NO}_{2}$ and $\mathrm{SO}_{2}$ vertical column densities at a rural site of North China, Atmos. Environ., 133, 12-25, $2016 \mathrm{a}$.

Jin, J., Ma, J., Lin, W., and Zhao, H.: Characteristics of $\mathrm{NO}_{2}$ Tropospheric column density over a rural area in the North China Plain (in Chinese), J. Appl. Meteorol. Sci., 27, 303-311, https://doi.org/10.11898/1001-7313.20160305, 2016 b.

Kanaya, Y., Irie, H., Takashima, H., Iwabuchi, H., Akimoto, H., Sudo, K., Gu, M., Chong, J., Kim, Y. J., Lee, H., Li, A., Si, F., Xu, J., Xie, P.-H., Liu, W.-Q., Dzhola, A., Postylyakov, O., Ivanov, V., Grechko, E., Terpugova, S., and Panchenko, M.: Long-term MAX-DOAS network observations of NO2 in Russia and Asia (MADRAS) during the period 2007-2012: instrumentation, elucidation of climatology, and comparisons with OMI satellite observations and global model simulations, Atmos. Chem. Phys., 14, 7909-7927, https://doi.org/10.5194/acp14-7909-2014, 2014.

Kleffmann, J., Gavriloaiei, T., Hofzumahaus, A., Holland, F., Koppmann, R., Rupp, L., Schlosser, E., Siese, M., and Wahner, A.: Daytime formation of nitrous acid: A major source of $\mathrm{OH}$ radicals in a forest, Geophys. Res. Lett., 32, L05818, https://doi.org/10.1029/2005GL022524, 2005.

Kraus, S.: DOASIS, A Framework Design for DOAS, PhDthesis, University of Mannheim, available at: http://hci.iwr. uni-heidelberg.de/publications/dip/2006/Kraus_PhD2006.pdf (last access: 20 September 2020), 2006.

Kreher, K., Van Roozendael, M., Hendrick, F., Apituley, A., Dimitropoulou, E., Frieß, U., Richter, A., Wagner, T., Lampel, J., Abuhassan, N., Ang, L., Anguas, M., Bais, A., Benavent, N., Bösch, T., Bognar, K., Borovski, A., Bruchkouski, I., Cede, A., Chan, K. L., Donner, S., Drosoglou, T., Fayt, C., Finkenzeller, H., Garcia-Nieto, D., Gielen, C., Gómez-Martín, L., Hao, N., Henzing, B., Herman, J. R., Hermans, C., Hoque, S., Irie, H., Jin, J., Johnston, P., Khayyam Butt, J., Khokhar, F., Koenig, T. K., Kuhn, J., Kumar, V., Liu, C., Ma, J., Merlaud, A., Mishra, A. K., Müller, 
M., Navarro-Comas, M., Ostendorf, M., Pazmino, A., Peters, E., Pinardi, G., Pinharanda, M., Piters, A., Platt, U., Postylyakov, O., Prados-Roman, C., Puentedura, O., Querel, R., Saiz-Lopez, A., Schönhardt, A., Schreier, S. F., Seyler, A., Sinha, V., Spinei, E., Strong, K., Tack, F., Tian, X., Tiefengraber, M., Tirpitz, J.L., van Gent, J., Volkamer, R., Vrekoussis, M., Wang, S., Wang, Z., Wenig, M., Wittrock, F., Xie, P. H., Xu, J., Yela, M., Zhang, C., and Zhao, X.: Intercomparison of $\mathrm{NO}_{2}, \mathrm{O}_{4}, \mathrm{O}_{3}$ and $\mathrm{HCHO}$ slant column measurements by MAX-DOAS and zenith-sky UVvisible spectrometers during CINDI-2, Atmos. Meas. Tech., 13, 2169-2208, https://doi.org/10.5194/amt-13-2169-2020, 2020.

Kurucz, R. L., Furenlid, I., Brault, J., and Testerman, L.: Solar Flux Atlas from 296 to $1300 \mathrm{~nm}$, in National Solar Observatory Atlas, Harvard Univ., Cambridge, Mass, 1984.

Lampel, J., Frieß, U., and Platt, U.: The impact of vibrational Raman scattering of air on DOAS measurements of atmospheric trace gases, Atmos. Meas. Tech., 8, 3767-3787, https://doi.org/10.5194/amt-8-3767-2015, 2015.

Lampel, J., Pöhler, D., Polyansky, O. L., Kyuberis, A. A., Zobov, N. F., Tennyson, J., Lodi, L., Frieß, U., Wang, Y., Beirle, S., Platt, U., and Wagner, T.: Detection of water vapour absorption around 363 ?nm in measured atmospheric absorption spectra and its effect on DOAS evaluations, Atmos. Chem. Phys., 17, 1271-1295, https://doi.org/10.5194/acp-17-1271-2017, 2017.

Li, X., Brauers, T., Shao, M., Garland, R. M., Wagner, T., Deutschmann, T., and Wahner, A.: MAX-DOAS measurements in southern China: retrieval of aerosol extinctions and validation using ground-based in-situ data, Atmos. Chem. Phys., 10, 20792089, https://doi.org/10.5194/acp-10-2079-2010, 2010.

Li, X., Brauers, T., Häseler, R., Bohn, B., Fuchs, H., Hofzumahaus, A., Holland, F., Lou, S., Lu, K. D., Rohrer, F., Hu, M., Zeng, L. M., Zhang, Y. H., Garland, R. M., Su, H., Nowak, A., Wiedensohler, A., Takegawa, N., Shao, M., and Wahner, A.: Exploring the atmospheric chemistry of nitrous acid (HONO) at a rural site in Southern China, Atmos. Chem. Phys., 12, 1497-1513, https://doi.org/10.5194/acp-12-1497-2012, 2012.

Li, X., Brauers, T., Hofzumahaus, A., Lu, K., Li, Y. P., Shao, M., Wagner, T., and Wahner, A.: MAX-DOAS measurements of $\mathrm{NO}_{2}, \mathrm{HCHO}$ and $\mathrm{CHOCHO}$ at a rural site in Southern China, Atmos. Chem. Phys., 13, 2133-2151, https://doi.org/10.5194/acp13-2133-2013, 2013.

Li, X., Rohrer, F., Hofzumahaus, A., Brauers, T., Häseler, R., Bohn, B., Broch, S., Fuchs, H., Gomm, S., Holland, F., and Jäger, J.: Missing gas-phase source of HONO inferred from Zeppelin measurements in the troposphere, Science, 344, 292-296, https://doi.org/10.1126/science.1248999, 2014.

Liu, M., Lin, J., Boersma, K. F., Pinardi, G., Wang, Y., Chimot, J., Wagner, T., Xie, P., Eskes, H., Van Roozendael, M., Hendrick, F., Wang, P., Wang, T., Yan, Y., Chen, L., and Ni, R.: Improved aerosol correction for OMI tropospheric NO2 retrieval over East Asia: constraint from CALIOP aerosol vertical profile, Atmos. Meas. Tech., 12, 1-21, https://doi.org/10.5194/amt-12-1-2019, 2019

Ma, J. Z., Beirle, S., Jin, J. L., Shaiganfar, R., Yan, P., and Wagner, T.: Tropospheric NO2 vertical column densities over Beijing: results of the first three years of ground-based MAXDOAS measurements (2008-2011) and satellite validation, Atmos. Chem. Phys., 13, 1547-1567, https://doi.org/10.5194/acp13-1547-2013, 2013.
Mayer, B. and Kylling, A.: Technical note: The libRadtran software package for radiative transfer calculations - description and examples of use, Atmos. Chem. Phys., 5, 1855-1877, https://doi.org/10.5194/acp-5-1855-2005, 2005.

Meller, R. and Moortgat, G. K.: Temperature dependence of the absorption cross sections of formaldehyde between 223 and $323 \mathrm{~K}$ in the wavelength range 225-375 nm, J. Geophys. Res., 105, 7089-7101, 2000.

Monks, P. S., Granier, C., Fuzzi, S., Stohl, A., Williams, M. L., Akimoto, H., Amann, M., Baklanov, A., Baltensperger, U., Bey, I., and Blake, N.: Atmospheric composition change-global and regional air quality, Atmos. Environ., 43, 5268-5350, 2009.

Nasse, J.-M., Eger, P. G., Pöhler, D., Schmitt, S., Frieß, U., and Platt, U.: Recent improvements of long-path DOAS measurements: impact on accuracy and stability of short-term and automated long-term observations, Atmos. Meas. Tech., 12, 41494169, https://doi.org/10.5194/amt-12-4149-2019, 2019.

Neftel, A., Blatter, A., Hesterberg, R., and Staffelbach, T.: Measurements of concentration gradients of $\mathrm{HNO}_{2}$ and $\mathrm{HNO}_{3}$ over a semi-natural ecosystem, Atmos. Environ., 30, 3017-3025, https://doi.org/10.1016/1352-2310(96)00011-8, 1996.

Ortega, I., Coburn, S., Berg, L. K., Lantz, K., Michalsky, J., Ferrare, R. A., Hair, J. W., Hostetler, C. A., and Volkamer, R.: The CU 2-D-MAX-DOAS instrument - Part 2: Raman scattering probability measurements and retrieval of aerosol optical properties, Atmos. Meas. Tech., 9, 3893-3910, https://doi.org/10.5194/amt9-3893-2016, 2016.

Ortega, I., Koenig, T., Sinreich, R., Thomson, D., and Volkamer, R.: The CU 2-D-MAX-DOAS instrument - Part 1: Retrieval of 3-D distributions of $\mathrm{NO}_{2}$ and azimuth-dependent OVOC ratios, Atmos. Meas. Tech., 8, 2371-2395, https://doi.org/10.5194/amt8-2371-2015, 2015.

Pagsberg, P., Bjergbakke, E., Ratajczak, E., and Sillesen A.: Kinetics of the gas phase reaction $\mathrm{OH}+\mathrm{NO}(+\mathrm{M}) \rightarrow \mathrm{O}(+\mathrm{M})$ and the determination of the UV absorption cross sections of HONO, Chem. Phys. Lett., 272, 383-390, https://doi.org/10.1016/S00092614(97)00576-9, 1997.

Peters, E., Pinardi, G., Seyler, A., Richter, A., Wittrock, F., Bösch, T., Van Roozendael, M., Hendrick, F., Drosoglou, T., Bais, A. F., Kanaya, Y., Zhao, X., Strong, K., Lampel, J., Volkamer, R., Koenig, T., Ortega, I., Puentedura, O., Navarro-Comas, M., Gómez, L., Yela González, M., Piters, A., Remmers, J., Wang, Y., Wagner, T., Wang, S., Saiz-Lopez, A., García-Nieto, D., Cuevas, C. A., Benavent, N., Querel, R., Johnston, P., Postylyakov, O., Borovski, A., Elokhov, A., Bruchkouski, I., Liu, H., Liu, C., Hong, Q., Rivera, C., Grutter, M., Stremme, W., Khokhar, M. F., Khayyam, J., and Burrows, J. P.: Investigating differences in DOAS retrieval codes using MAD-CAT campaign data, Atmos. Meas. Tech., 10, 955-978, https://doi.org/10.5194/amt-10-9552017, 2017.

Peters, E., Ostendorf, M., Bösch, T., Seyler, A., Schönhardt, A., Schreier, S. F., Henzing, J. S., Wittrock, F., Richter, A., Vrekoussis, M., and Burrows, J. P.: Full-azimuthal imaging-DOAS observations of $\mathrm{NO}_{2}$ and $\mathrm{O}_{4}$ during CINDI-2, Atmos. Meas. Tech., 12, 4171-4190, https://doi.org/10.5194/amt-12-4171-2019, 2019.

Pinardi, G., Van Roozendael, M., Abuhassan, N., Adams, C., Cede, A., Clémer, K., Fayt, C., Frieß, U., Gil, M., Herman, J., Hermans, C., Hendrick, F., Irie, H., Merlaud, A., Navarro Comas, M., Peters, E., Piters, A. J. M., Puentedura, O., Richter, A., Schön- 
hardt, A., Shaiganfar, R., Spinei, E., Strong, K., Takashima, H., Vrekoussis, M., Wagner, T., Wittrock, F., and Yilmaz, S.: MAXDOAS formaldehyde slant column measurements during CINDI: intercomparison and analysis improvement, Atmos. Meas. Tech., 6, 167-185, https://doi.org/10.5194/amt-6-167-2013, 2013.

Piters, A. J. M., Boersma, K. F., Kroon, M., Hains, J. C., Van Roozendael, M., Wittrock, F., Abuhassan, N., Adams, C., Akrami, M., Allaart, M. A. F., Apituley, A., Beirle, S., Bergwerff, J. B., Berkhout, A. J. C., Brunner, D., Cede, A., Chong, J., Clémer, K., Fayt, C., Frieß, U., Gast, L. F. L., Gil-Ojeda, M., Goutail, F., Graves, R., Griesfeller, A., Großmann, K., Hemerijckx, G., Hendrick, F., Henzing, B., Herman, J., Hermans, C., Hoexum, M., van der Hoff, G. R., Irie, H., Johnston, P. V., Kanaya, Y., Kim, Y. J., Klein Baltink, H., Kreher, K., de Leeuw, G., Leigh, R., Merlaud, A., Moerman, M. M., Monks, P. S., Mount, G. H., Navarro-Comas, M., Oetjen, H., Pazmino, A., Perez-Camacho, M., Peters, E., du Piesanie, A., Pinardi, G., Puentedura, O., Richter, A., Roscoe, H. K., Schönhardt, A., Schwarzenbach, B., Shaiganfar, R., Sluis, W., Spinei, E., Stolk, A. P., Strong, K., Swart, D. P. J., Takashima, H., Vlemmix, T., Vrekoussis, M., Wagner, T., Whyte, C., Wilson, K. M., Yela, M., Yilmaz, S., Zieger, P., and Zhou, Y.: The Cabauw Intercomparison campaign for Nitrogen Dioxide measuring Instruments (CINDI): design, execution, and early results, Atmos. Meas. Tech., 5, 457-485, https://doi.org/10.5194/amt-5457-2012, 2012.

Platt, U. and Stutz, J.: Differential Optical Absorption Spectroscopy. Springer-Verlag Heidelberg, Berlin, 229-375, 2008.

Polyansky, O. L., Kyuberis, A. A., Lodi, L., Tennyson, J., Ovsyannikov, R. I., and Zobov, N.: ExoMol molecular line lists XIX: high-accuracy computed hot line lists for $\mathrm{H}_{2}^{18} \mathrm{O}$ and $\mathrm{H}_{2}^{17} \mathrm{O}$, Mon. Not. R. Astron. Soc., 466, 1363-1371, 2016.

Pukite, J., Kühl, S., Deutschmann, T., Platt, U., and Wagner, T.: Extending differential optical absorption spectroscopy for limb measurements in the UV, Atmos. Meas. Tech., 3, 631-653, https://doi.org/10.5194/amt-3-631-2010, 2010.

Rodgers, C. D.: Inverse methods for atmospheric sounding, theory and practice, Series on Atmospheric, Oceanic and Planetary Physics, World Scientific, 2000.

Rohrer, F., Bohn, B., Brauers, T., Brüning, D., Johnen, F.-J., Wahner, A., and Kleffmann, J.: Characterisation of the photolytic HONO-source in the atmosphere simulation chamber SAPHIR, Atmos. Chem. Phys., 5, 2189-2201, https://doi.org/10.5194/acp5-2189-2005, 2005.

Roscoe, H. K., Van Roozendael, M., Fayt, C., du Piesanie, A., Abuhassan, N., Adams, C., Akrami, M., Cede, A., Chong, J., Clémer, K., Friess, U., Gil Ojeda, M., Goutail, F., Graves, R., Griesfeller, A., Grossmann, K., Hemerijckx, G., Hendrick, F., Herman, J., Hermans, C., Irie, H., Johnston, P. V., Kanaya, Y., Kreher, K., Leigh, R., Merlaud, A., Mount, G. H., Navarro, M., Oetjen, H., Pazmino, A., Perez-Camacho, M., Peters, E., Pinardi, G., Puentedura, O., Richter, A., Schönhardt, A., Shaiganfar, R., Spinei, E., Strong, K., Takashima, H., Vlemmix, T., Vrekoussis, M., Wagner, T., Wittrock, F., Yela, M., Yilmaz, S., Boersma, F., Hains, J., Kroon, M., Piters, A., and Kim, Y. J.: Intercomparison of slant column measurements of $\mathrm{NO}_{2}$ and $\mathrm{O}_{4}$ by MAXDOAS and zenith-sky UV and visible spectrometers, Atmos. Meas. Tech., 3, 1629-1646, https://doi.org/10.5194/amt-3-16292010, 2010.
Rozanov, A., Rozanov, V., Buchwitz, M., Kokhanovsky, A., and Burrows, J.: SCIATRAN 2.0 - A new radiative transfer model for geophysical applications in the $175-2400 \mathrm{~nm}$ spectral region, in: Atmospheric Remote Sensing: Earth's Surface, Troposphere, Stratosphere and Mesosphere - I, edited by: Burrows, J. and Eichmann, K., vol. 36 of ADVANCES IN SPACE RESEARCH, 1015-1019, 2005.

Rozanov, V. V., Rozanov, A. V., Kokhanovsky, A. A., and Burrows, J. P.: Radiative transfer through terrestrial atmosphere and ocean: software package SCIATRAN, J. Quant. Spectrosc. Ra. Trans., 133, 13-71, 2014.

Ryan, R. G., Rhodes, S., Tully, M., Wilson, S., Jones, N., Frieß, U., and Schofield, R.: Daytime HONO, $\mathrm{NO}_{2}$ and aerosol distributions from MAX-DOAS observations in Melbourne, Atmos. Chem. Phys., 18, 13969-13985, https://doi.org/10.5194/acp-1813969-2018, 2018.

Spurr, R.: LIDORT and VLIDORT: Linearized pseudo-spherical scalar and vector discrete ordinate radiative transfer models for use in remote sensing retrieval problems, Light Scattering Reviews, Volume 3, edited by: Kokhanovsky, A., Springer, 2008.

Spurr, R.: User's Guide VLIDORT Version 2.6, RT Solutions, Inc., 2013.

Sörgel, M., Regelin, E., Bozem, H., Diesch, J.-M., Drewnick, F., Fischer, H., Harder, H., Held, A., Hosaynali-Beygi, Z., Martinez, M., and Zetzsch, C.: Quantification of the unknown HONO daytime source and its relation to $\mathrm{NO}_{2}$, Atmos. Chem. Phys., 11, 10433-10447, https://doi.org/10.5194/acp-11-104332011, 2011.

Stuhl, F. and Niki H.: Flash photochemical study of the reaction $\mathrm{OH}+\mathrm{NO}+\mathrm{M}$ using resonance fluorescent detection of OH, J. Chem. Phys., 57, 3677-3679, https://doi.org/10.1063/1.1678826, 1972.

Stutz, J., Kim, E. S., Platt, U., Bruno, P., Perrino, C., and Febo, A.: UV-vis Absorption Cross-Section of Nitrous Acid, J. Geophys. Res., 105, 14585-14592, 2000.

Su, H., Cheng, Y., Oswald, R., Behrendt, T., Trebs, I., Meixner, F. X., Andreae, M. O., Cheng, P., Zhang, Y., and Pöschl, U.: Soil nitrite as a source of atmospheric HONO and OH radicals, Science, 333, 1616-1618, https://doi.org/10.1126/science.1207687, 2011.

Su, H., Cheng, Y. F., Shao, M., Gao, D. F., Yu, Z. Y., Zeng, L. M., Slanina, J., Zhang, Y. H., and Wiedensohler, A.: Nitrous acid (HONO) and its daytime sources at a rural site during the 2004 PRIDE-PRD experiment in China, J. Geophys. Res.-Atmos., 113, D14312, https://doi.org/10.1029/2007JD009060, 2008.

Serdyuchenko, A., Gorshelev, V., Weber, M., Chehade, W., and Burrows, J. P.: High spectral resolution ozone absorption crosssections - Part 2: Temperature dependence, Atmos. Meas. Tech., 7, 625-636, https://doi.org/10.5194/amt-7-625-2014, 2014.

Thalman, R. M. and Volkamer, R.: Temperature Dependent Absorption Cross-Sections of $\mathrm{O}_{2}-\mathrm{O}_{2}$ collision pairs between 340 and $630 \mathrm{~nm}$ and at atmospherically relevant pressure, Phys. Chem. Chem. Phys., 15, 15371-15381, https://doi.org/10.1039/c3cp50968k, 2013.

Tirpitz, J.-L., Frieß, U., Hendrick, F., Alberti, C., Allaart, M., Apituley, A., Bais, A., Beirle, S., Berkhout, S., Bognar, K., Bösch, T., Bruchkouski, I., Cede, A., Chan, K. L., den Hoed, M., Donner, S., Drosoglou, T., Fayt, C., Friedrich, M. M., Frumau, A., Gast, L., Gielen, C., Gomez-Martín, L., Hao, N., Hensen, A., Henzing, B., 
Hermans, C., Jin, J., Kreher, K., Kuhn, J., Lampel, J., Li, A., Liu, C., Liu, H., Ma, J., Merlaud, A., Peters, E., Pinardi, G., Piters, A., Platt, U., Puentedura, O., Richter, A., Schmitt, S., Spinei, E., Stein Zweers, D., Strong, K., Swart, D., Tack, F., Tiefengraber, M., van der Hoff, R., van Roozendael, M., Vlemmix, T., Vonk, J., Wagner, T., Wang, Y., Wang, Z., Wenig, M., Wiegner, M., Wittrock, F., Xie, P., Xing, C., Xu, J., Yela, M., Zhang, C., and Zhao, X.: Intercomparison of MAX-DOAS vertical profile retrieval algorithms: studies on field data from the CINDI-2 campaign, Atmos. Meas. Tech. Discuss., https://doi.org/10.5194/amt-2019456, in review, 2020.

Van Roozendael, M., Fayt, C., Post, P., Hermans, C., Lambert, J.C.: Retrieval of $\mathrm{BrO}$ and $\mathrm{NO}_{2}$ from UV-Visible Observations, in: Sounding the troposphere from space: a new Era for Atmospheric Chemistry. The TROPOSAT Final Report, edited by: Borrell, P., Borrell, P. M., Burrows, J. P., and Platt, U., Springer Verlag, 155166, 2003.

Vandaele, A. C., Hermans, C., Simon, P. C., Carleer, M., Colin, R., Fally, S., Mérienne, M.-F., Jenouvrier, A., and Coquart, B.: Measurements of the $\mathrm{NO}_{2}$ absorption cross section from $42000 \mathrm{~cm}^{-1}$ to $10000 \mathrm{~cm}^{-1}(238-1000 \mathrm{~nm})$ at $220 \mathrm{~K}$ and $294 \mathrm{~K}$, J. Quant. Spectrosc. Ra., 59, 171-184, 1998.

Vlemmix, T., Piters, A. J. M., Stammes, P., Wang, P., and Levelt, P. F.: Retrieval of tropospheric NO2 using the MAXDOAS method combined with relative intensity measurements for aerosol correction, Atmos. Meas. Tech., 3, 1287-1305, https://doi.org/10.5194/amt-3-1287-2010, 2010.

Vlemmix, T., Piters, A. J. M., Berkhout, A. J. C., Gast, L. F. L., Wang, P., and Levelt, P. F.: Ability of the MAX-DOAS method to derive profile information for $\mathrm{NO}_{2}$ : can the boundary layer and free troposphere be separated?, Atmos. Meas. Tech., 4, 26592684, https://doi.org/10.5194/amt-4-2659-2011, 2011.

Vlemmix, T., Hendrick, F., Pinardi, G., De Smedt, I., Fayt, C., Hermans, C., Piters, A., Wang, P., Levelt, P., and Van Roozendael, M.: MAX-DOAS observations of aerosols, formaldehyde and nitrogen dioxide in the Beijing area: comparison of two profile retrieval approaches, Atmos. Meas. Tech., 8, 941-963, https://doi.org/10.5194/amt-8-941-2015, 2015

Wagner, T., B. Dix, C. von Friedeburg, Frieß, U., Sanghavi, S., Sinreich, R., and Platt, U.: MAX-DOAS $\mathrm{O}_{4}$ measurements: A new technique to derive information on atmospheric aerosols - Principles and information content, J. Geophys. Res., 109, D22205, https://doi.org/10.1029/2004JD004904, 2004.

Wagner, T., Beirle, S., and Deutschmann, T.: Three-dimensional simulation of the Ring effect in observations of scattered sun light using Monte Carlo radiative transfer models, Atmos. Meas. Tech., 2, 113-124, https://doi.org/10.5194/amt-2113-2009, 2009.

Wagner, T., Beirle, S., Brauers, T., Deutschmann, T., Frieß, U., Hak, C., Halla, J. D., Heue, K. P., Junkermann, W., Li, X., Platt, U., and Pundt-Gruber, I.: Inversion of tropospheric profiles of aerosol extinction and $\mathrm{HCHO}$ and $\mathrm{NO}_{2}$ mixing ratios from MAX-DOAS observations in Milano during the summer of 2003 and comparison with independent data sets, Atmos. Meas. Tech., 4, 2685-2715, https://doi.org/10.5194/amt-4-2685-2011, 2011.

Wagner, T., Apituley, A., Beirle, S., Dörner, S., Friess, U., Remmers, J., and Shaiganfar, R.: Cloud detection and classification based on MAX-DOAS observations, Atmos. Meas. Tech., 7, 1289-1320, https://doi.org/10.5194/amt-7-1289-2014, 2014.
Wagner, T., Beirle, S., Remmers, J., Shaiganfar, R., and Wang, Y.: Absolute calibration of the colour index and $\mathrm{O}_{4}$ absorption derived from Multi AXis (MAX-)DOAS measurements and their application to a standardised cloud classification algorithm, Atmos. Meas. Tech., 9, 4803-4823, https://doi.org/10.5194/amt-94803-2016, 2016.

Wang, Y., Li, A., Xie, P. H., Chen, H., Xu, J., Wu, F. C., Liu, J. G., and Liu, W. Q.: Retrieving vertical profile of aerosol extinction by multi-axis differential optical absorption spectroscopy, Acta Phys. Sin., 16, 180705, https://doi.org/10.7498/aps.62.180705, 2013a.

Wang, Y., Li, A., Xie, P. H., Chen, H., Mou, F. S., Xu, J., Wu, F. C., Zeng, Y., Liu, J. G., and Liu, W. Q.: Measuring tropospheric vertical distribution and vertical column density of $\mathrm{NO}_{2}$ by multiaxis differential optical absorption spectroscopy, Acta Phys. Sin., 62, 200705, 2013b.

Wang, Y., Li, A., Xie, P. H., Wagner, T., Chen, H., Liu, W. Q., and Liu, J. G.: A rapid method to derive horizontal distributions of trace gases and aerosols near the surface using multi-axis differential optical absorption spectroscopy, Atmos. Meas. Tech., 7 , 1663-1680, https://doi.org/10.5194/amt-7-1663-2014, 2014.

Wang, Y., Penning de Vries, M., Xie, P. H., Beirle, S., Dörner, S., Remmers, J., Li, A., and Wagner, T.: Cloud and aerosol classification for 2.5 years of MAX-DOAS observations in Wuxi (China) and comparison to independent data sets, Atmos. Meas. Tech., 8, 5133-5156, https://doi.org/10.5194/amt-8-5133-2015, 2015.

Wang, Y., Beirle, S., Lampel, J., Koukouli, M., De Smedt, I., Theys, N., Li, A., Wu, D., Xie, P., Liu, C., Van Roozendael, M., Stavrakou, T., Müller, J.-F., and Wagner, T.: Validation of OMI, GOME-2A and GOME-2B tropospheric $\mathrm{NO}_{2}, \mathrm{SO}_{2}$ and $\mathrm{HCHO}$ products using MAX-DOAS observations from 2011 to 2014 in Wuxi, China: investigation of the effects of priori profiles and aerosols on the satellite products, Atmos. Chem. Phys., 17, 50075033, https://doi.org/10.5194/acp-17-5007-2017, 2017a.

Wang, Y., Lampel, J., Xie, P., Beirle, S., Li, A., Wu, D., and Wagner, T.: Ground-based MAX-DOAS observations of tropospheric aerosols, $\mathrm{NO}_{2}, \mathrm{SO}_{2}$ and $\mathrm{HCHO}$ in Wuxi, China, from 2011 to 2014, Atmos. Chem. Phys., 17, 2189-2215, https://doi.org/10.5194/acp-17-2189-2017, 2017 b.

Wang, Y., Beirle, S., Hendrick, F., Hilboll, A., Jin, J., Kyuberis, A. A., Lampel, J., Li, A., Luo, Y., Lodi, L., Ma, J., Navarro, M., Ortega, I., Peters, E., Polyansky, O. L., Remmers, J., Richter, A., Puentedura, O., Van Roozendael, M., Seyler, A., Tennyson, J., Volkamer, R., Xie, P., Zobov, N. F., and Wagner, T.: MAX-DOAS measurements of HONO slant column densities during the MAD-CAT campaign: inter-comparison, sensitivity studies on spectral analysis settings, and error budget, Atmos. Meas. Tech., 10, 3719-3742, https://doi.org/10.5194/amt10-3719-2017, 2017c.

Wang, Y., Dórner, S., Donner, S., Böhnke, S., De Smedt, I., Dickerson, R. R., Dong, Z., He, H., Li, Z., Li, Z., Li, D., Liu, D., Ren, X., Theys, N., Wang, Y., Wang, Y., Wang, Z., Xu, $\mathrm{H}$., $\mathrm{Xu}, \mathrm{J}$. , and Wagner, T.: Vertical profiles of $\mathrm{NO}_{2}, \mathrm{SO}_{2}$, HONO, HCHO, CHOCHO and aerosols derived from MAXDOAS measurements at a rural site in the central western North China Plain and their relation to emission sources and effects of regional transport, Atmos. Chem. Phys., 19, 5417-5449, https://doi.org/10.5194/acp-19-5417-2019, 2019. 
Wang, Y., Puíte, J., Wagner, T., Donner, S., Beirle, S., Hilboll, A., Vrekoussis, M., Richter, A., Apituley, A., Piters, A., and Allaart, M.: Vertical Profiles of Tropospheric Ozone From MAX-DOAS Measurements During the CINDI-2 Campaign: Part 1 - Development of a New Retrieval Algorithm, J. Geophys. Res.-Atmos., 123, 10-637, 2018b.

Wittrock, F., Oetjen, H., Richter, A., Fietkau, S., Medeke, T., Rozanov, A., and Burrows, J. P.: MAX-DOAS measurements of atmospheric trace gases in Ny-Ålesund - Radiative transfer studies and their application, Atmos. Chem. Phys., 4, 955-966, https://doi.org/10.5194/acp-4-955-2004, 2004.

Wittrock, F.: The Retrieval of Oxygenated Volatile Organic Compounds by Remote Sensing Techniques. Ph.D., University of Bremen, Bremen, Germany, available at: http://www. doas-bremen.de/paper/diss_wittrock_06.pdf (last access: December 2015), 2006.
Wong, K. W., Tsai, C., Lefer, B., Haman, C., Grossberg, N., Brune, W. H., Ren, X., Luke, W., and Stutz, J.: Daytime HONO vertical gradients during SHARP 2009 in Houston, TX, Atmos. Chem. Phys., 12, 635-652, https://doi.org/10.5194/acp-12-6352012, 2012.

Yilmaz, S.: Retrieval of Atmospheric Aerosol and Trace Gas Vertical Profiles using Multi-Axis Differential Optical Absorption Spectroscopy, $\mathrm{PhD}$ thesis, University of Heidelberg, Germany, 2012.

Zieger, P., Weingartner, E., Henzing, J., Moerman, M., de Leeuw, G., Mikkilä, J., Ehn, M., Petäjä, T., Clémer, K., van Roozendael, M., Yilmaz, S., Frieß, U., Irie, H., Wagner, T., Shaiganfar, R., Beirle, S., Apituley, A., Wilson, K., and Baltensperger, U.: Comparison of ambient aerosol extinction coefficients obtained from in-situ, MAX-DOAS and LIDAR measurements at Cabauw, Atmos. Chem. Phys., 11, 2603-2624, https://doi.org/10.5194/acp11-2603-2011, 2011. 